\title{
ABSORÇÃO, CONCENTRAÇÃO E EXPORTAÇÃO DE NUTRIENTES PELA COLZA (Brassioa napus) EM FUNÇÃO DA IDADE
}

\author{
MARIA ANITA GONÇALVES DA SILVA CASARINI
}

Orientador: Prof. Dr. HENRIQUE PAULO HAAG

Dissertação apresentada à Escola Superior de Agricultura "Luiz de Queiroz", da Universidade de São Paulo, para obtenção do titulo de Mestre em Agronomia. Área de Concentração: Solos $\theta$ Nutrição de Plantas.

PIR A CICABA

Estado de São Paulo - Brasil

Novembro - 1983 
i i.

\author{
Aos meus irmãos, minha mãe e ao meu pai, \\ que sempre me estimulou e que \\ sempre vai estar comigo.
}

OFERECOO.

A meu marido

LUIZ ALBERTO

DEDICO. 
iii.

\section{AGRADECIMENTOS}

Ao Prof. Dr. Henrique Paulo Hag.

Ao Engo Agrônomo Gedi Jorge Sfredo.

$\bar{A}$ Escola Superior de Agricultura "Luiz de Queiroz", Universidade de São Paulo.

Ao Conselho Nacional de Desenvolvimento Científico e Tecnológico ( $\mathrm{CNPq})$.

A todos que direta ou indiretamente, contribuiram para o êxito deste trabalho. 
I N D I C E

Pägina

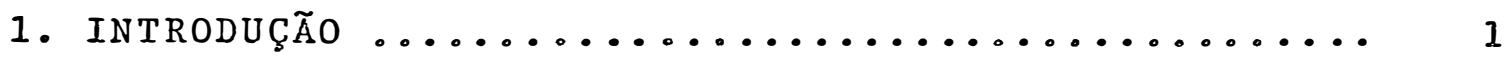

2. REVISÃo de Literatura $\ldots \ldots \ldots \ldots \ldots \ldots \ldots \ldots \ldots \ldots$

3. MATERIAL E MÉTODOS ....................... 18

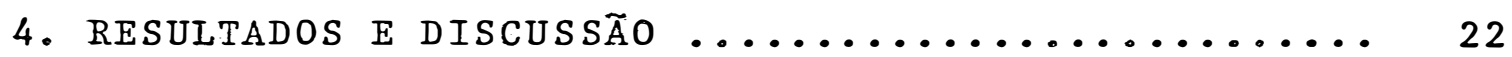

4.1. Crescimento ..................... 22

4.2. Macronutrientes .................... 24

4.2.1. Nitrogēnio ................. 24

4.2.1.1. Concentração ........... 24

4.2.1.2. Acúmulo ............. 27

4.2.2. Fósforo $\ldots \ldots \ldots \ldots \ldots \ldots \ldots \ldots \ldots . \ldots \ldots$

4.2.2.1. Concentração ............ 29

4.2.2.2. Acúmulo .............. 31

4.2.3. Potássio ..................... 34

4.2.3.1. Concentração ............ 34

4.2.3.2. Acúmulo .............. 34

4.2.4: Eálcio ................... 37

4.2.4.1. Concentração .......... 37

4.2.4.2. Acümulo ............. 39

4.2.5. Magrésio .................... 42

4.2.5.1. Concentração ........... 42

4.2.5.2. Acūmulo ............. 42 
4.2 .6$. Enxofre .................. 45

4.2 .6 .1$. Concentração .......... 45

4.2 .6 .2 . Acúmulo $\ldots \ldots \ldots \ldots \ldots \ldots 4$

4.3. Micronutrientes .................. 50

4.3 .1 . Boro ......................... 50

4.3.1.1. Concentração ........... 50

4.3.1.2.Acúmulo ............. 50

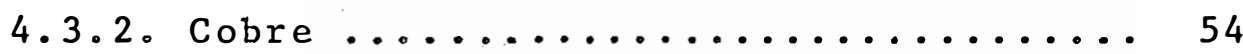

4.3.2.1. Concentração ........... 54

4.3.2.2. Acūmulo ............... 54

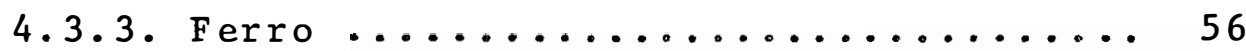

4.3.3.1. Concentração .......... 56

4.3.3.2. Acúmulo ............. 59

4.3.4. Manganês .................... 60

4.3 .4 .1 . Concentração ........... 60

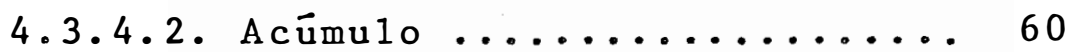

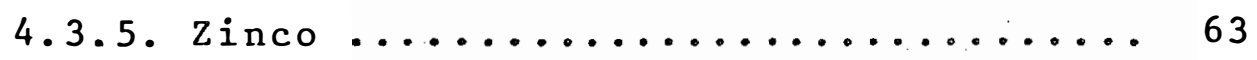

4.3.5.1. Concentração ...........6 63

4.3.5.2. Acūmulo ...............63 63

4.4. Exportação de nutrientes pela colza ...... 65

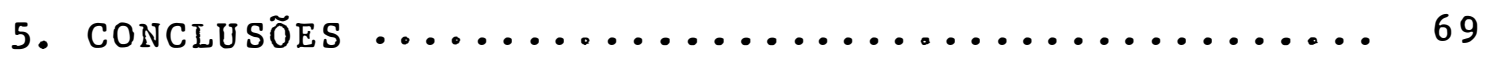

5.1. Crescimento .............................. 69

5.2. Concentração de nutrientes ............. 69

5.3. Acúmulo de nutrientes ................. 70

5.4. Exportação de nutrientes pelas sementes na

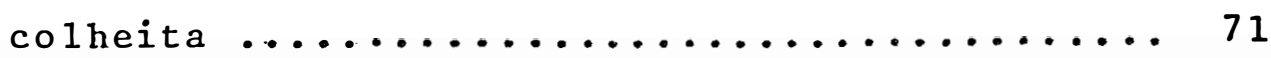

6. Literatura citAdA .................... 72 
ABSORÇAO, CONCENTRAÇÃO E EXPORTAÇÃO DE NUTRIENTES PELA COLZA (Brassica napus), EM FUNÇÃO DA IDADE.

Candidata: Maria Anita Gonçalves da Silva Casarini

Orientador: Henrique Paulo Hag

RESUMO

Com o objetivo de se estudar a marcha de absorção de macro e micronutrientes pela colza (Brassica napus), instalou-se um experimento no campo experimental do Departamento de Agricultura e Horticultura da Escola Supe rior de Agricultura "Luiz de Queiroz", USP, Piracicaba (SP). Determinou-se a curva de crescimento da planta, o acúmu10 de nutrientes e a concentração de nutrientes das 1 inhagens $(1504$ e 1530).

O experimento foi conduzido em 1980, em con dições de campo, no solo argiloso Terra Roxa Estruturada, sẹ rie Luiz de Queiroz.

o delineamento estatístico foi o inteiramente casualizado com quatro repetições. Utilizou-se 5 trata- 
mentos, em duas parcelas de $5 \times 20 \mathrm{~m}$, relativos a épocas de amostragem. As épocas foram aos 50, 80, 106, 134 e 168 dias após a semeadura: Na semeadura usou-se um espaçamento de 0,30 m entre plantas e $1,00 \mathrm{~m}$ entre linhas, deixando-se uma densidade de 3 plantas a cada $90 \mathrm{~cm}$, correspondendo a uma população de 333 plantas por parcela e 33.333 plantas/ha.

Após cada amostragem as plantas foram separa das em raiz, caule, folha, flor, vagem e semente e analisadàs quimicamente para o nitrogênio, fósforo, potássio, cálcio, magnésio, enxofre, boro, cobre, ferro, manganês e zin co.

Nas condições em que o experimento foi condu zido pode-se concluir que:

- o ponto de máximo desenvolvimento da planta e produção de matéria seca é atingido aos 142 e 168 dias, após a semeadura, para as linhagens 1504 e 1530 , respectivamente. O desenvolvimento da planta é lento até aos 80 dias, acentuando-se após esse período.

- As concentrações dos macro e micronutrientes diminuem com o aumento da quantidade de matéria seca, mostrando o efeito de diluição.

- O acúmulo dos macronutrientes, bem como, dos micronutrientes boro, cobre e zinco é baixo até os 
vi i

80 dias, no início do florescimento aumentando significativamente aos 106 dias, em pleno florescimento com um máximo atin gido no fim do florescimento, entre 120 e 139 dias, para as duas linhagens e a 164 dias para o cobre na linhagem 1504 .

- o acúmulo dos micronutrientes ferro e manganês é baixo até aos 80 dias, no inîcio do florescimento, sendo crescente e gradativo até o fim do ciclo.

- A ordem na absorção de nutrientes é a seguinte: $\mathrm{K}>\mathrm{N}>\mathrm{Ca}>\mathrm{S}>\mathrm{P}>\mathrm{Mg}>\mathrm{Fe}>\mathrm{Mn}>\mathrm{B}>\mathrm{Zn}>\mathrm{Cu}$

- A ordem de exportação dos nutrientes é: $\mathrm{N}>\mathrm{P}>\mathrm{K}=\mathrm{Ca}>\mathrm{S}>\mathrm{Mg}>\mathrm{Mn}>\mathrm{Fe}>\mathrm{Zn}>\mathrm{B}>\mathrm{Cu}$ 
ABSORPTION, CONCENTRATION AND EXPORTATION OF NUTRIENTS BY RAPE (Brassica napus) PLANTS IN FUNCTION OF THE AGE.

Candidate: Maria Anita Gonçalves da Silva Casarini

Adviser: Henrique Paulo Hag

SUMMARY

With the objective to study the course of absorption the macronutrients and micronutrients by the rape (Brassica napus) in function of the age of the plant, one experiment was carried out in the experimental field of the Department of Agriculture and Horticulture of Escola Superior de Agricultura "Luiz de Queiroz", USP, in Piracicaba, SP.

The experiment was lead out in the agricultural year of 1,980, in field condition, in Terra Roxa Estruturada soil (A1fiso1).

The statistics design obey a completely randomized blocs, with four repetitions. Plants were collected from $50,80,106,134$ and 168 days o $1 d$.

The space of $0.30 \mathrm{~m}$ between plants and $1.00 \mathrm{~m}$ between lines, were used a density of 3 plants for linear metre, corresponding to a population of 333 plants for plot or 33,333 plants/ha. 
After each sample the plants was separated into roots, stalks, leaves, flowers, pods and seeds and analized for nitrogen, phosphorous, potassium, calcium, magnesium, sulfur, boron, copper, iron, manganese and zinc.

The maine conclusions are:

- The maximum development of the plant and production of dry matter is reached on 142 and 179 days after the semeadure, for the strains 1504 and 1530 , respectively. The development of the plant in rather slow until 80 days.

- The concentration of the macronutrients and micronutrients decrease with the increase of the amount of dry matter.

- The increase of the macronutrients and micro nutrients content in boro, copper and zinc is low until 80 days at the beginning of flowering, increasing significantly at 106 days, in full blooming, with on maximum increase reached in the end of blooming between 120 and 139 days, for the two strains.

- The micronutrients content in iron and manganese is low until the 80 days. At the beginning of the flowering, increasing gradual until the end of the plant cycle.

- The absorption of nutrients obey the following order: $\mathrm{K}>\mathrm{N}>\mathrm{Ca}>\mathrm{S}>\mathrm{P}>\mathrm{Mg}>\mathrm{Fe}>\mathrm{Mn}>\mathrm{B}>\mathrm{Zn}>\mathrm{Cu}$.

- The order of exportation of the nutrients by the grains obey the following order: $\mathrm{N}>\mathrm{P}>\mathrm{K}=\mathrm{Ca}>\mathrm{S}>\mathrm{Mg}>$ $\mathrm{Mn}>\mathrm{Fe}>\mathrm{Zn}>\mathrm{B}>\mathrm{Cu}$ 。 
1. INTRODUÇÃO

A colza é una planta da familia das Crucífe ras, pertencente ao Gênero Brassica. E uma planta herbácea anual de inverno, que pode alcançar a altura de 1,30 a $1,80 \mathrm{~m}$ nas condições do RS. Possui floṛes amarelas, frutos em siliquas, com 5 a $7 \mathrm{~cm}$ de comprimento, com sementes pequenas, arredondadas, cascanho escura (Comitê dacol$\mathrm{za}, \mathrm{RS})$.

Suas sementes contêm 40 a $50 \%$ de seu peso em óleo, sendo duas vezes mais elevado que a soja, oleaginosa de maior produção no Brasil. Além disso, a Colza tem $22 \%$ de pro teínas em suas sementes (HEMERLY, 1979).

No Brasil, a cultura estā em fase de estudos e pesquisas, principalmente noRio Grande do Sul, com a finalida 
de de ocupar grande parte da área ociosa não ocupada com otri go. No período de inverno, o trigo passou a estar em apenas uma quarta parte da área ocupada com a soja, vindo a Colza ocupar o restante da área, racionalmente nesse estado.

E uma cultura de fácil manejo, exigindo os mesmos equipamentos usados para a soja e o trigo, com pequenos ajustes (Comitê da Colza, RS).

Em fase de testes das variedades importadas, fo ram obtidos rendimentos entre 1.800 a $3.000 \mathrm{~kg} / \mathrm{ha}$, através da Cooperativa Triticola de Ijuí (Cotrijuí), no Rio Grande do Sul. Ela jà é cultivada nesse estado por muitos associados a essa cooperativa, em Ijuì (HEMERLY, 1979).

Na literatura, os trabalhos sobre nutrição mine ral são bem poucos, principalmente relativos aos micronutrientes.

Havendo necessidade de informações bāsicas sobre o crescimento e nutrição mineral dessa hortaliça foi conduzido trabalho de campo visando:

1) Determinar o crescimento das plantas, através da produção de matéria seca.

2) Extração e acúmulo dos nutrientes em função 
da idade da planta。

3) Concentração de macro e micronutrientes, em função da idade da planta.

4) Exportação de nutrientes pelas sementes. 


\section{REVISAO DE LITERATURA}

RADET (1955), em Champagne, na França, empregan do niveis de 100 a $250 \mathrm{~kg} \mathrm{~N} / \mathrm{ha}, 160 \mathrm{~kg} \mathrm{P} 2 \mathrm{O}_{5} / \mathrm{ha}, 300 \mathrm{~kg} \mathrm{~K} 20 / \mathrm{ha}$ e 50,80 e $120 \mathrm{~kg} \mathrm{~S} / \mathrm{ha}$, em diferentes épocas, encontrou para um cultivar de outono uma absorção contỉnua de nitrogênio, fós foro, cálcio e enxôfre, durante todo o desenvolvimento da plan ta. SChultz (1972), na Dinamarca; STUder (1969) na França; RACZ (1965), no Canadä e LEON (1978), na Espanha, verificaram o mes mo em relação ao nitrogênio absorvido. A absorção continnua do fósforo também foi encontrada por BRIOUX (1923), LOUISE e PICARD (1891), LEFEVRE (1957), RADET (1956), na França; SCHULTz (1972), na Dinamcarca e RACZ (1965), no Canadá. A absorção do cálcio foi a mesma para LOUISE e PICARD (1891), na França e a absorção do enxôfre foi igualmente encontrada por RADET (1956), STUDER (1969) e BRIOUX (1923), na França e SCHULTz (1972), na Dinamarca. 
0 potássio e o magnésio se encontraram na planta em quantidades crescentes até pleno florescimento, diminuindo a partir daí. o mesmo foi encontrado em relação ao potássio, por Radet (1952), citado por ROLliER (1970), RADET(1956) STUDER (1969), ROLLIER (1969) e LEFEVRE (1957), na França, LEON (1978), na Espanha e ANDERSON et alii (1958), na Suécia. Esses ultimos autores encontraram o mesmo resultado encontrado por RADET (1955) em relação ao magnésio absorvido pela planta.

RADET (1956), em Marne, na França, empregando niveis de $125,0,187,5$ e $250 \mathrm{~kg} \mathrm{~N} / \mathrm{ha} ; 175,0 \mathrm{~kg} \mathrm{P}{ }_{2} \mathrm{O}_{5} / \mathrm{ha}$; $300 \mathrm{~K}_{2} \mathrm{O} / \mathrm{ha}$ e 50,80, $120 \mathrm{~kg} \mathrm{~s} / \mathrm{ha}$ em diferentes épocas de aplicação encontrou para um cultivar de outono, absorção contĩnua do nitrogênio até o início do florescimento, diminuindo até o início da maturação dos grãos, aumentando depois até ofim do ciclo. Esse mesmo resultado foi também encontrado por BRIOUX (1923), na França.

o magnésio foi absorvido pela planta em quantidades crescentes até a colheita. LOUISE e PICARD (1891), COURPRON et alii (1973), na França e SCHULTz (1972), na Dinamarca, confirmam os dados de RADET (1956).

COURPRON et alii (1973), na França, mostraram as necessidades minerais do cultivar Sarepta, usando $180 \mathrm{~kg} /$ ha de $\mathrm{N}$ e $\mathrm{K}_{2} \mathrm{O} ; 120 \mathrm{~kg} \mathrm{P}{ }_{2} \mathrm{O}_{5} / \mathrm{ha} ; 50 \mathrm{~kg} \mathrm{~S} / \mathrm{ha}$ e 1,0 a $2,0 \mathrm{t} / \mathrm{ha}$ de 
calcārio, em diferentes épocas de aplicação. o nitrogênio,fós foro, potássio e enxôfre, tiveram absorção contínua até o ini cio da maturação dos grãos, dimimuindo a partir daí até o final da maturação e colheita dos grãos. STuder (1969) e Radet (1952), citado por ROLLIER (1970), na França, encontraram o mesmo resultado para o fósforo absorvido, havendo a mesma semelhança para o enxôfre absorvido, segundo RoLliER (1969), na França.

O cálcio teve uma absorção gradativa, até pleno florescimento, diminuindo depois até o início da maturação dos grãos, onde novamente aumentou.

ROLLIER (1969), na França, estudou os nutrientes requeridos por um cultivar de outono submetidos a $150 \mathrm{~kg}$ $\mathrm{N} / \mathrm{ha}, 190 \mathrm{~kg} \mathrm{P}{ }_{2} \mathrm{O}_{5} / \mathrm{ha}$ e $225 \mathrm{~kg} \mathrm{~K} \mathrm{~K}_{2} / \mathrm{ha}$. A absorção de nitrogênio foi crescente até o pleno florescimento da planta, diminuindo a partir daî até o início da maturação dos grãos, aumentan do novamente até a colheita.

o cálcio foi encontrado em quantidades crescen tes na planta até o início da maturação dos grãos, diminuindo depois até o final do ciclo.

ANDERSON et alii (1958) empregando níveis de 300 a $400 \mathrm{~kg} \mathrm{P}_{2} \mathrm{O}_{5} / \mathrm{ha}$ e 150 a $300 \mathrm{~kg} \mathrm{~K}{ }_{2}$ /ha, em três $10 \mathrm{calidades}$ da Suécia, encontraram absorção contínua do nitrogênio, fósforo, 
cálcio e magnésio até o fim do florescimento, diminuindo depois até o fim da maturação dos grãos. A mesma sequência na ab sorção do nitrogênio foi encontrada por LEFẼVR (1957), LOUISE e PICARD (1891), na França e RACZ (1965), no Canadá. Para LEON (1978), na Espanha, o fósforo teve o mesmo cumportamento.

SCHULTZ (1972), na Dinamarca, em estudos sobre acúmulo e distribuição de nutrientes em um cultivar de outono submetidos a $186,0 \mathrm{~kg} \mathrm{~N} / \mathrm{ha}, 35 \mathrm{~kg} \mathrm{P} 2 \mathrm{O}_{5} / \mathrm{ha}$ e $91 \mathrm{~kg} \mathrm{~K} 20 / \mathrm{ha}$, con cluiu que há maior acūmulo durante o outono, nas folhas e caules e no final do florescimento, nas folhas, vagens e sementes. As raizes tiveram menor quantidade de nutrientes, em todos os estádio de desenvolvimento da planta.

o potássio foi absorvido continuamente até o final do ciclo, concordando com os ensaios de BRIOUX (1923) e LOUISE e PICARD (1891), na França.

STUDER (1969), na França, mostrou as necessidades nutricionais de um cultivar de inverno, em Champagne, submetido a doses variáveis de 180 a $220 \mathrm{~kg} \mathrm{~N} / \mathrm{ha}, 120$ a $150 \mathrm{~kg}$ $\mathrm{P}_{2} \mathrm{O}_{5} / \mathrm{ha}$ e 100 a $120 \mathrm{~kg} \mathrm{~K} 20 /$ ha 0 s resultados sobre o acúmulo dos nutrientes foram semelhantes aos encontrados pelos autores mencionados.

PIERRE (1860), na França, estudando o crescimen 
to de Colza de inverno, concluiu que o nitrogênio, fósforo e cálcio eram mais importantes para a cultura até o pleno flores cimento, tornanäo-se menos exigidos depois.

LEFEVRE (1957), na França, usando uma população de 250 a 800.000 plantas/ha e aplicando doses de 100, 150 e $200 \mathrm{~kg} \mathrm{~N} / \mathrm{ha}$, em diferentes épocas, avaliou o comportamento de um cultivar de outono. Os resultados sobre a exigencia nutricional, foram comuns aos autores já mencionados.

RACZ (1965), no Canadā, estudando a utilização do nitrogênio e fósforo em cultivar de verão, Golden usando $63 \mathrm{~kg} \mathrm{~N} / \mathrm{ha}$ e $23 \mathrm{~kg}$ P/ha e cultivo alternado e não alternado com Colza, verificou que há maior absorção dos dois nutrientes, quando se alternava a cultura. Os resultados sobre o acūmulo dos nutrientes foram comuns aos encontrados pelos autores mencionados.

Em geral, todos os autores encontraram rápida absorção dos nutrientes entre o início do florescimento e ple no florescimento, nas épocas de março a maio, podendo ser menor a partir do florescimento ou iñٌcio da maturação.

Os resultados sobre a extração dos nutrientes em fases distintas do crescimento da cultura estão na Tabela 1 , em $\mathrm{kg} / \mathrm{ha}$, de acordo com diversos autores. 


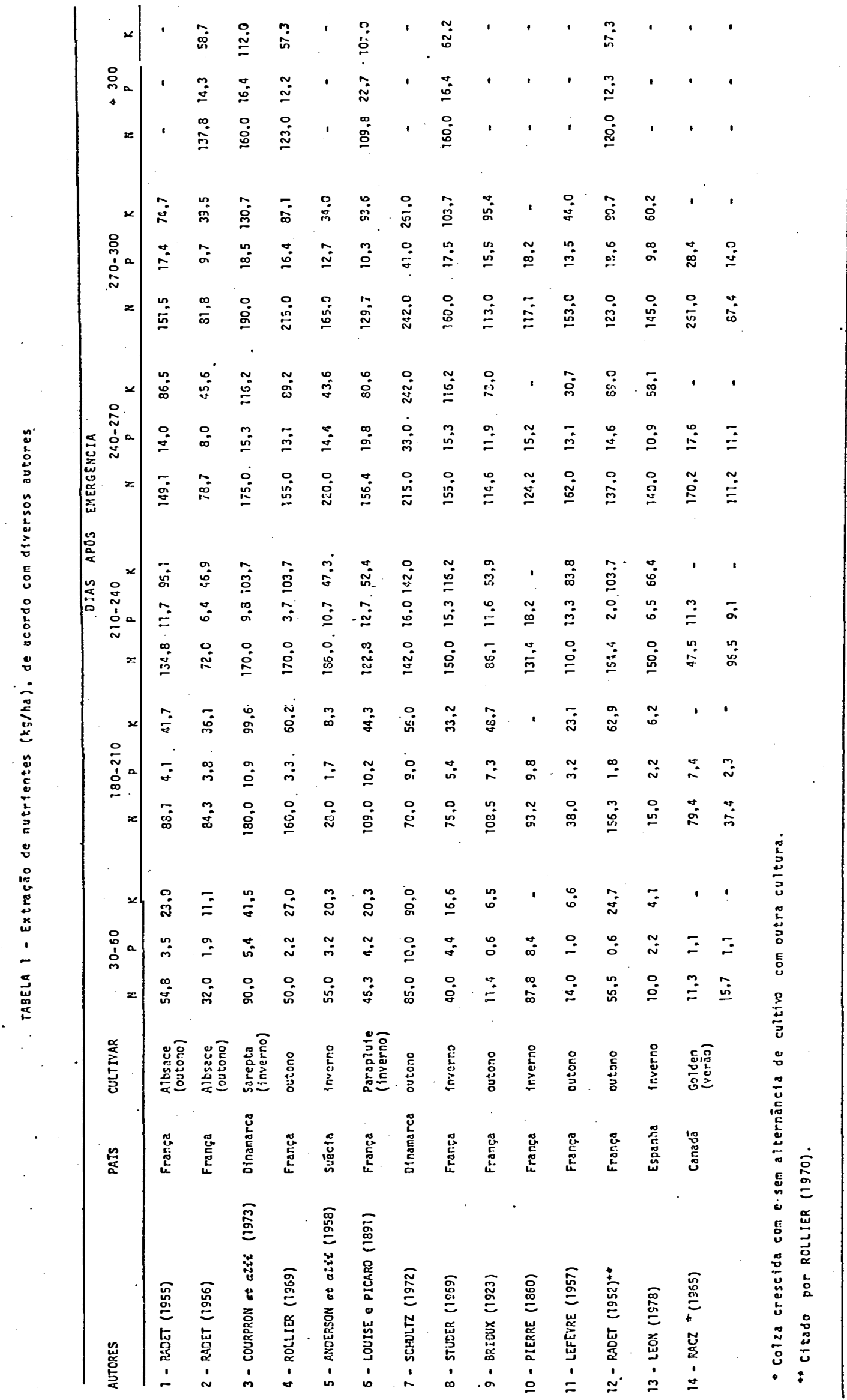




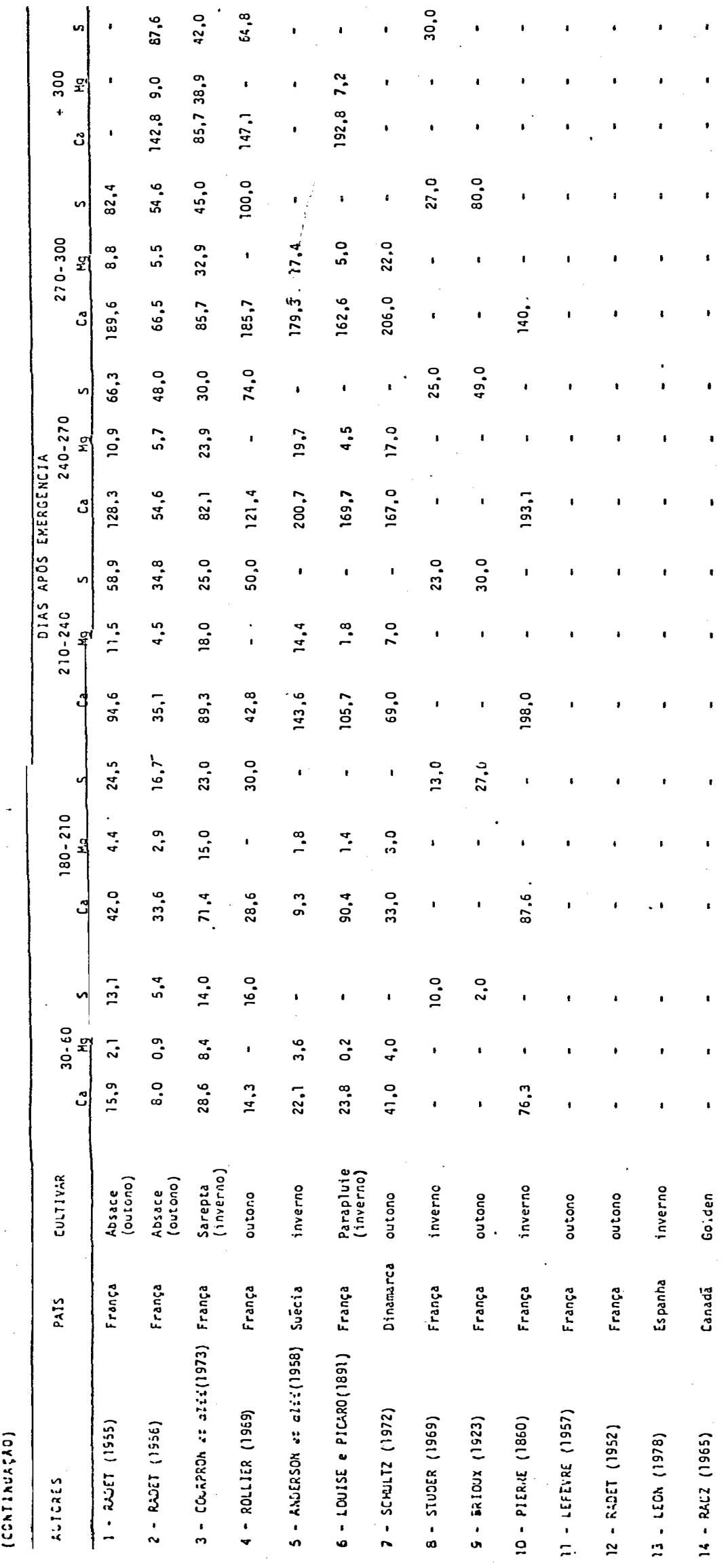


A extração total dos macro e micronutrientes, no fim do ciclo da cultura é dado a seguir pelos autores.

MAJUMDAR (1965), na India, testou nîveis de nitrogênio e fósforo no solo e épocas de semeadura para comparar tamanho de semente e extração de nutrientes, usando um culti var de outono. Considerando $56 \mathrm{~kg} / \mathrm{ha}$ de nitrogênio e fósforo no solo, a absorção total de nitrogênio pela planta foi de 67 $\mathrm{kg} / \mathrm{ha}$ e de fósforo foi de $16 \mathrm{~kg} / \mathrm{ha}$ no fim do ciclo.

ROLLIER (1970), na França, trabalhando com cultivar de outono, encontrou quantidades totais absorvidas de ni trogênio, fósforo e potássio variáveis com o local do experimento.

Em Versailles, a absorção total de nitrogênio, fósforo e potássio foi de $143,0,13,1$ e $38,6 \mathrm{~kg} / \mathrm{ha}$, respectivamente. Em Dijon, encontrou $121,0,7,2$ e $36,9 \mathrm{~kg} / \mathrm{ha}$. Em Mulhouse, encontrou $124,0,9,2$ e 78,0, respectivamente para os três nutrientes.

MIKOS (1976), na Polônia, avaliou as condições do solo e níveis de adubação, usando 120,80 a 100 e $120 \mathrm{~kg} / \mathrm{ha}$ de $\mathrm{N}_{2} \mathrm{P}_{2} \mathrm{O}_{5}$ e $\mathrm{K}_{2} \mathrm{O}$, no conteúdo de micronutrientes de um culti var de inverno. As quantidades encontradas, nas diversas partes da planta, na época da colheita, em ppm, encontram-se a seguir: 
o ferro foi encontrado em maior quantidade nas folhas, flores e raízes。o zinco, nas folhas, flores, vagens e caule. Os outros micronutrientes encontravam-se em maior quantidade nas flores, vagens e folhas.

GLINSKI et alii (1973), na Polônia, determinaram o conteúdo e distribuição dos micronutrientes em um cultivar de inverno, em diversas partes da planta. o ferrofoi encontrado em maior quantidade nas folhas, flores e raizes. $0 \mathrm{Zn}$, nas folhas, flores, vagens e caule, concordando ambos, com os dados encontrados por MIKOS (1976). Os outros micronutrientes encontram-se em maior quantidade nas flores, vagens e folhas. As con centrações dos micronutrientes, em ppm, nas partes da planta estão colocadas a seguir:

\section{Concentração dos micronutrientes na Colza}

Autor

MIKOS (1976)

GLINSKI (1973)

MIKOS (1976)

GLINSKI (1973)

MIKOS (1976)

GLINSKI (1973)

MIKOS (1976)

GLINSKI (1973)

MIKOS (1976)

GLINSKI (1973)

MIKOS (1976)

GLINSKI (1973)

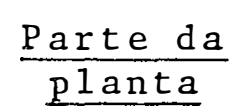

$$
\text { raiz }
$$$$
\text { raiz }
$$

caule

caule

folha

fol ha

flor

flor

vagem

vagem

semente

semente $\quad 11,3$

13,1

9,6

9,1

17,1

24,3

32,3

18,1 $\frac{\text { Concentração em }}{\mathrm{Cu}}$

$\mathrm{B} \quad \mathrm{Cu} \quad \mathrm{Fe} \quad \mathrm{Mn} \quad \mathrm{Zn}$

9,0

3,6

131,1

$33,3 \quad 80,0$

8,3

331,5

$51,2 \quad 53,6$

4,4

52,2

40,0

112,7

5,7

164,0

38,6

82,5

13,9

5,3

195,4

126,

164,1

8,3

261,7

157,0

186,3

6,8

169,5

$71,8 \quad 107,0$

8,2

350,0

$87,0 \quad 152,3$

14,9

6,4

92,2

$78,8 \quad 105,0$

7,7

297,0

150,

67,3

3,9

89,2

$48,1 \quad 72,9$

6,2

135,0

$63,1 \quad 70,1$ 
GERATH et alii (1975), na Alemanha, considera 30 ppm de boro nas folhas jovens, a quantidade limite para um bom desenvolvimento do cultivar Sollux, e estabelece o período antes do florescimento, como melhor para a determinação desse elemento na planta.

RUSZKOWSKA e LYSZCZ (1975), na Polônia, verifica ram o teor de cobre requerido pelo cultivar Mazur de primavera, em solos arenosos e turfosos. Considerando um teor de N, P2O5 e $\mathrm{K}_{2} 0 \mathrm{de} 525,420$ e $630 \mathrm{~kg} / \mathrm{ha}$ e $7 \mathrm{mg}$ de cobre, houve aumento do cobre antes e durante o florescimento, na parte aérea. Na maturação, há, para a mesma quantidade de adubo usado, diminuição do teor nas folhas e caules e aumento nas vagens, sementes e raízes, onde se encontrou 1,57, 0,38, 2,12, 3,98 e 3,48 ppm de cobre.

A Tabela 2 apresenta a extração de nutrientes pelas sementes em $\mathrm{kg} / \mathrm{ha}$, citados pelos diversos autores, consi derando um rendimento calculado de grãos de 1 t/ha. o nitrogênio é o nutriente mais removido pelas sementes, seguido do enxôfre e fósforo. Os menos extraỉdos foram o cálcio e o magnésio concordando com os resultados apontados na Tabela 4, relativa a concentração de nutrientes nos grãos.

A concentração dos nutrientes diminui com o aumento da matéria seca e crescimento da planta. Isso pode ser visto na Tabela 3 , segundo diversos autores. 


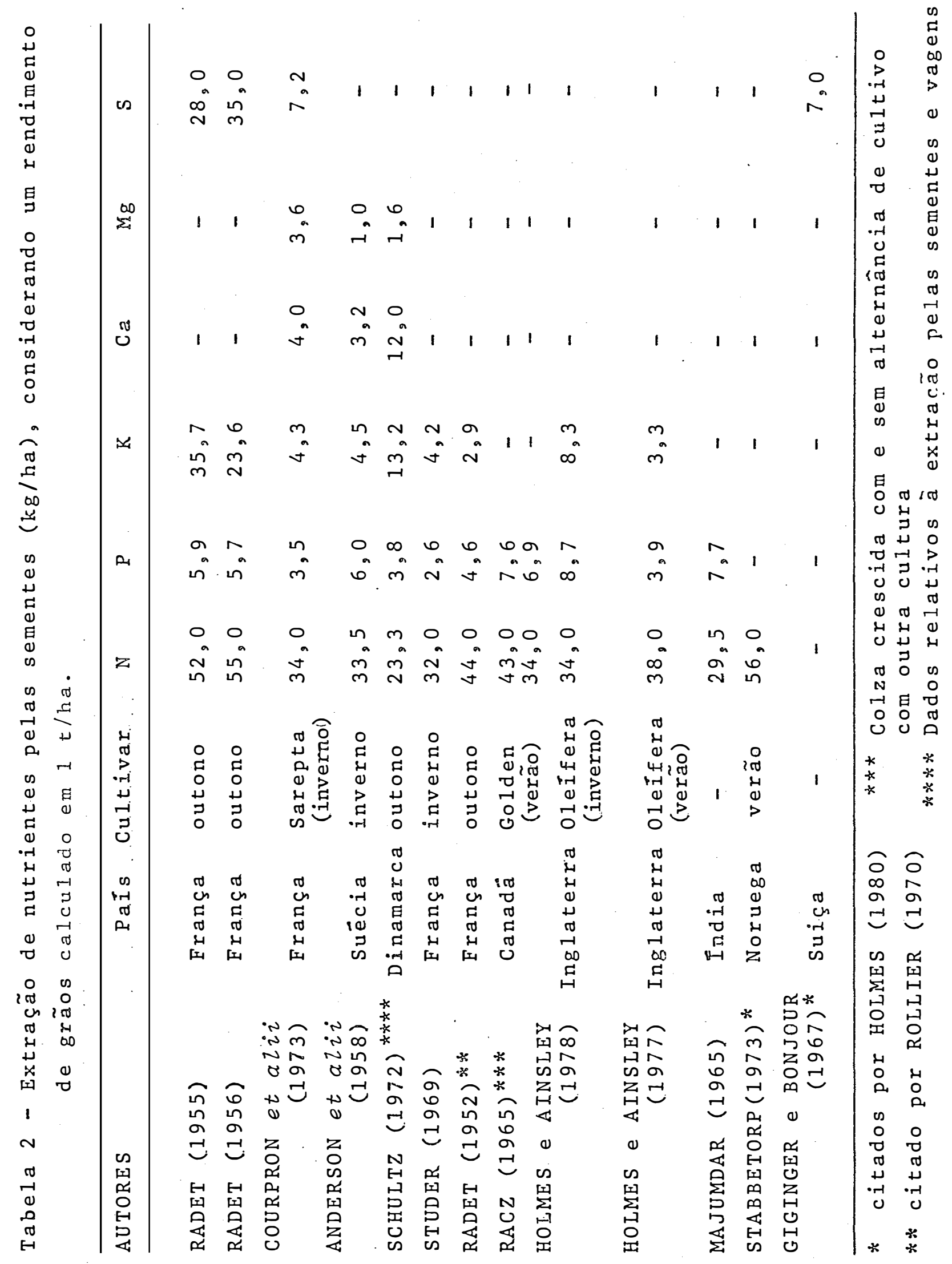




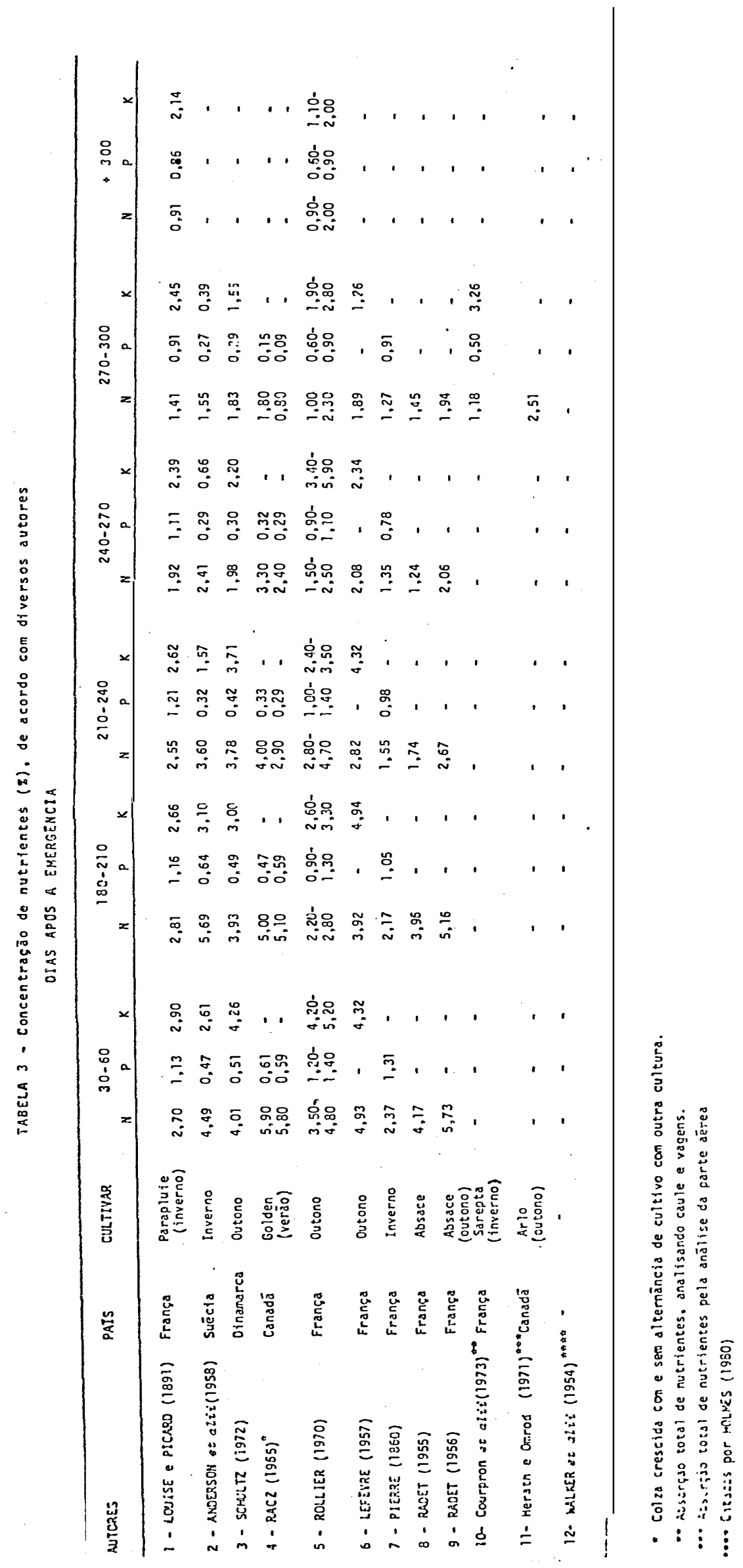




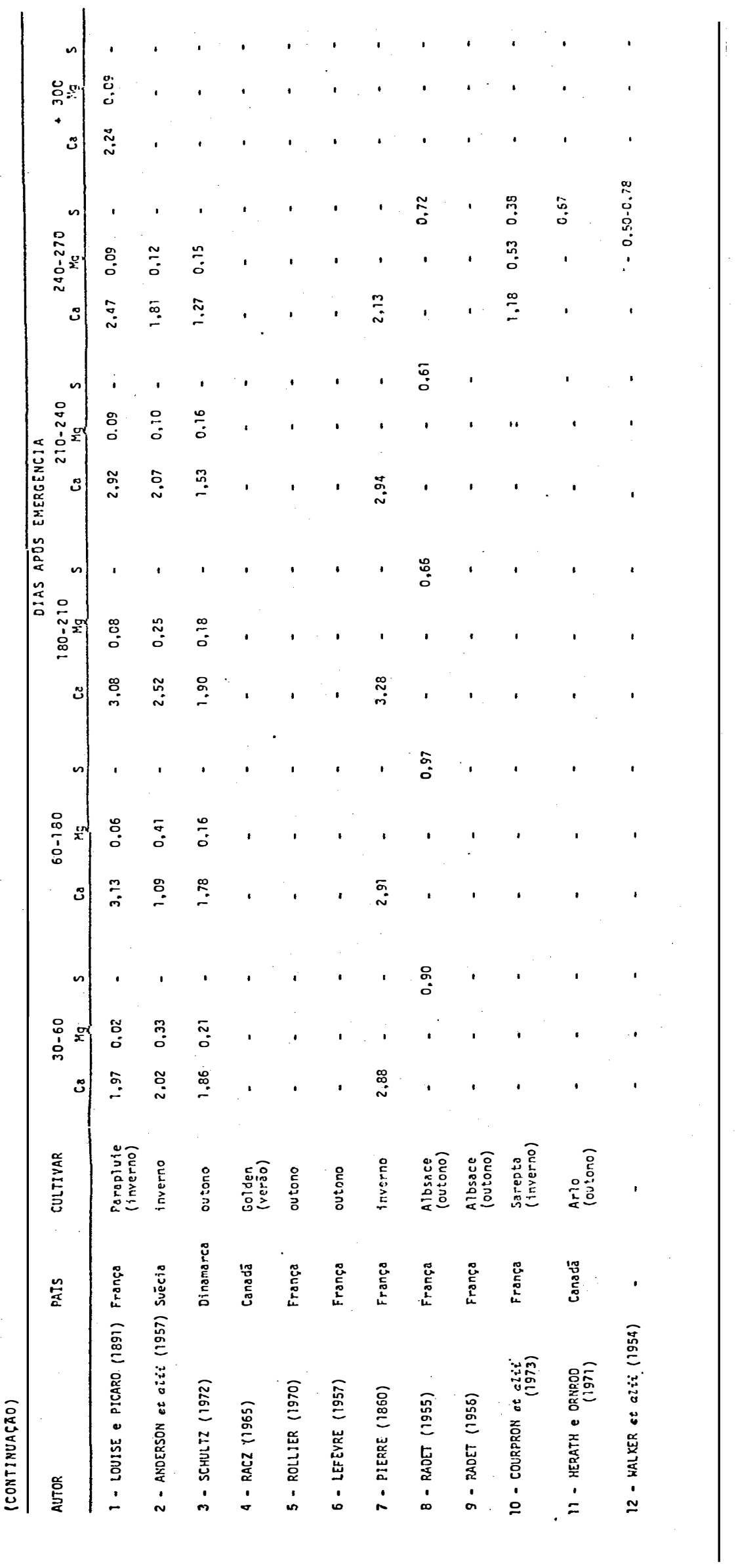




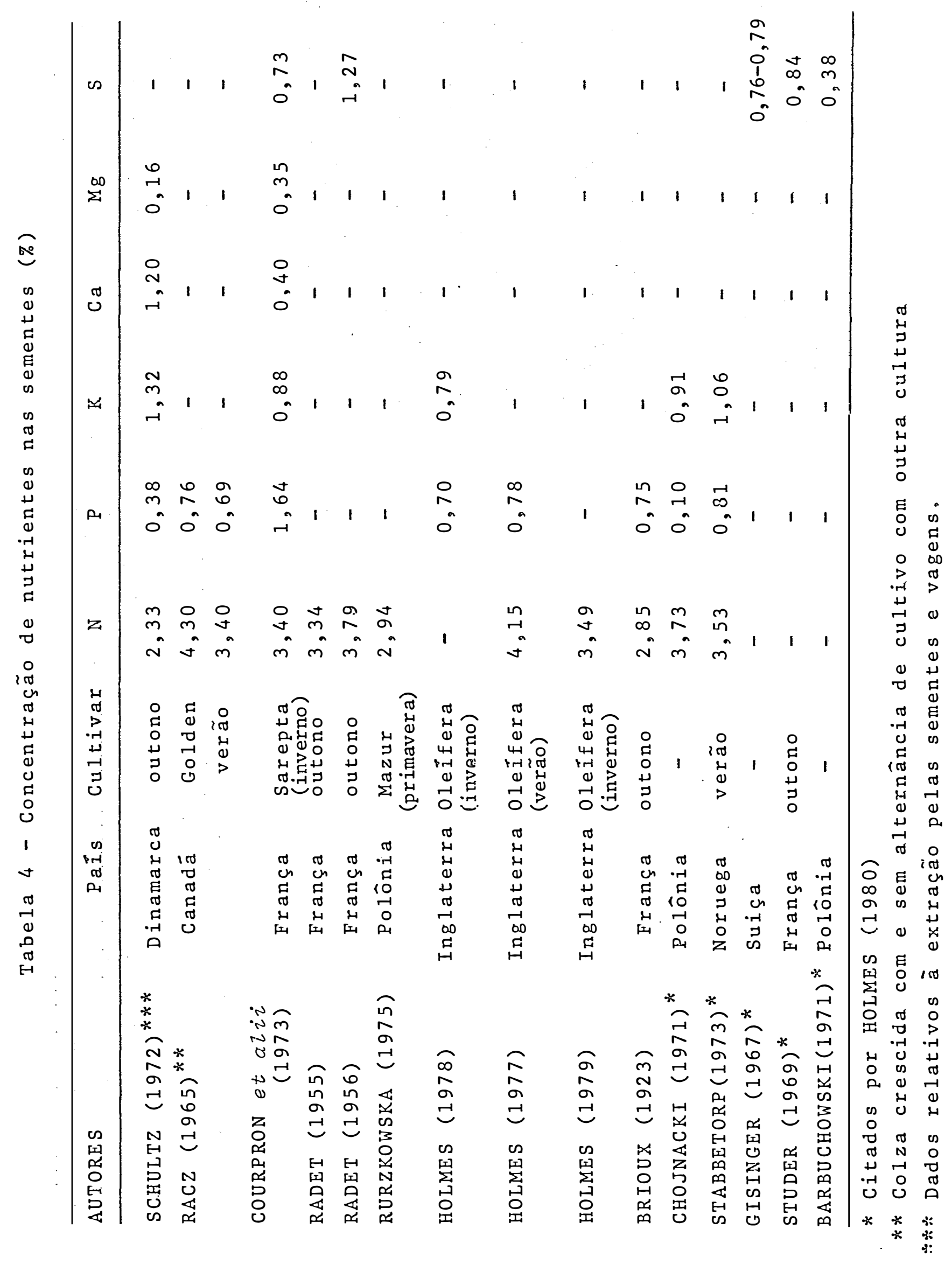




\section{MATERIAL E METODOS}

Foram utilizadas sementes das linhagens de Colza (Brassica napus) 1504 e 1530, procedentes da Cooperativa Re gional Tritícola Serrana, Cotrijuí, do RS.

o ensaio foi conduzido no campo experimental do Departamento de Agricultura e Horticultura da Escola Superior de Agricultura "Luiz de Queiroz", USP, no município de Piraci$\mathrm{caba}, \mathrm{SP}$.

SETZEP. (1946) classifica o clima local como meso

térmico a sub-tropical úmido, com estiagem no inverno. A temperatura média do mês mais quente é superior a $22^{\circ} \mathrm{C}$ e a do mês mais frio é inferior a $18^{\circ} \mathrm{C}$.

o solo utilizado é classificado como Terra Roxa Estruturada, série Luiz de Queiroz (RANZANI et alii, 1966 ) 
e vem sendo cultivado por anos consecutivos com hortaliças.

Antes do plantio foi retirada uma amostra com posta da camada arável, a $20 \mathrm{~cm}$ de profundidade na área experi mental, para a análise química dos nutrientes. Os resultados são apresentados a seguir:

$\mathrm{pH} \quad \% \mathrm{C} \quad$ emg/100 ml TFSA

$\left(\mathrm{H}_{2} \mathrm{O} \quad 1: 2,5\right)$

$$
\mathrm{PO}_{4}^{3-} * \mathrm{~K}^{+} \mathrm{Ca}^{2+}+\mathrm{Mg}^{2+} \mathrm{AI}^{3+}
$$
5,9
3,0
$1,0 \cdot 0,27$
13,10
0,00

* miliequivalente/100 g TFSA solúveis em HzSO4 0,05N.

A área total do campo foi dividida em duas parcelas distanciadas de $2,0 \mathrm{~m}$, com separação das 1 inhagens. A área das parcelas foi de $100 \mathrm{~m}^{2}$ sendo $5 \mathrm{~m}$ de 1 argura e $20 \mathrm{~m}$ de comprimento, com 333 plantas em cada parcela.

A semeadura no campo foi feita dia 26 de maio de 1980, com uma densidade de sementes de $0,5 \mathrm{~g} / \mathrm{m}$, colocadas em 6 linhas, distanciadas de $1,0 \mathrm{~m}$. A distância entre as plan tas foi de $0,30 \mathrm{~m}$, segundo recomendações da Cooperativa Triti cola, no Rio Grande do Sul.

A adubação das parcelas foi feita seguindo as 
recomendações de FILGUEIRA (1981), para repolho, constando da fórmula 4-16-8, na base de 300 g por metro linear. 0 nitrogênio em cobertura, na forma de sulfato de amônio foi aplicado na base de $15 \mathrm{~g} / \mathrm{m}$. linear, dividido em três aplicações, aos 20 , 45 e 60 dias após semeadura das plantas.

A irrigação das parcelas foi feita durante 40 dias, duas vezes por semana no sulco e nos outros 60 dias, uma vez por semana, segundo FILGUEIRA (1981), recomendando tratos culturais para a couve-flor.

o tratamento fitossanitário incluiu três pulve rizações preventivas com Endrex*, em intervalos de 20 dias e 8 pulverizações com Benlate** e Dithane $M-45^{* * *}$.

Durante o ensaio, com o desenvolvimento da planta foram colhidas amostras em cinco épocas, aos 50, 80, 106, 134 e 168 dias após a emergência. As amostragens foram feitas ao acaso, havendo quatro repetiçöes para cada parcela.

As plantas foram retiradas do solo e levadas ao laboratório, sendo separadas em raíz, folhas, caule, flor, va-

* Endrin (hexacloro epoxi octahidro dimetanonaftaleno

** Benomyl (metil benzimidazol carbamato)

*** Maneb (etileno bisditiocarbamato de manganês com zinco) 
gens e semente. Após a separação, as partes foram lavadas com água destilada e desmineralizada, segundo SARRUGE e HAAG (1974)。 Depois foram secas em estufa com circulaçãoforçada de ar a $7 \cdot 5^{\circ} \mathrm{C}$, determinando-se o peso da matéria seca.

A anālise química para nutrientes, exceto molibdênio e cloro, foi feita seguindo métodos descritos por SARRUGE $e$ HAAG (1974)。

Procedeu-se a anālise de variâncias e anālise de regressão, referentes à produção de matériaseca e extração dos nutrientes das duas 1 inhagens. 


\section{RESULTADOS E DISCUSSÃO}

\subsection{Crescimento}

o crescimento expresso pelo acúmulo da matéria seca, encontra-se na Tabela 5, juntamente com a análise estatística.

Evidencia-se maior produção de matéria seca pela linhagem 1530, porém, essa diferença só é significativa na última amostragem, demonstrando um desenvolvimento mais prolongado dessa 1 inhagem.

A Tabela 5 mostra fases distintas de crescimen to de acordo com as diferentes épocas de amostragem. Aos 50 dias após a semeadura da planta, no início do seu desenvolvimento vegetativo, o crescimento é pequeno, aumentando aos 80 dias, no início do florescimento, porém, sem diferença signi 
Tabela 5 - Resultados obtidos sobre a produção de matéria seca nas diversas partes da planta para as linhagens 1504 e 1530 em g/planta e kg/ha (Total de plantas/ ha 33.333 ).

\begin{tabular}{|c|c|c|c|c|}
\hline \multirow{2}{*}{$\begin{array}{l}\text { Dias apōs } \\
\text { emergencia }\end{array}$} & \multicolumn{2}{|c|}{$g / p l$} & \multicolumn{2}{|c|}{$\mathrm{kg} / \mathrm{ha}$} \\
\hline & 1504 & 1530 & 1504 & 1530 \\
\hline 50 & $6,15 \mathrm{Ba}$ & $6,75 \mathrm{Ba}$ & 205,0 & 225,0 \\
\hline 80 & $22,92 \mathrm{Ba}$ & $34,27 \mathrm{Ba}$ & 764,0 & 1142,3 \\
\hline 106 & $69,97 \mathrm{Aa}$ & $78,10 \mathrm{Aa}$ & 2332,3 & 2603,3 \\
\hline 134 & $82,10 \mathrm{Aa}$ & $101,40 \mathrm{Aa}$ & 2736,6 & 3380,0 \\
\hline 168 & $66,30 \mathrm{Ab}$ & $107,90 \mathrm{Aa}$ & 2203,3 & 3596,6 \\
\hline
\end{tabular}

$\mathrm{dms}$ (Tukey) $5 \%=37,92$

$\mathrm{C} . \mathrm{V} . \quad=32,83 \%$

Tabela 6 - Resultados referentes à época de maior absorção e a quantidade maxima acumulada de matéria seca nas linhagens 1504 e 1530 。

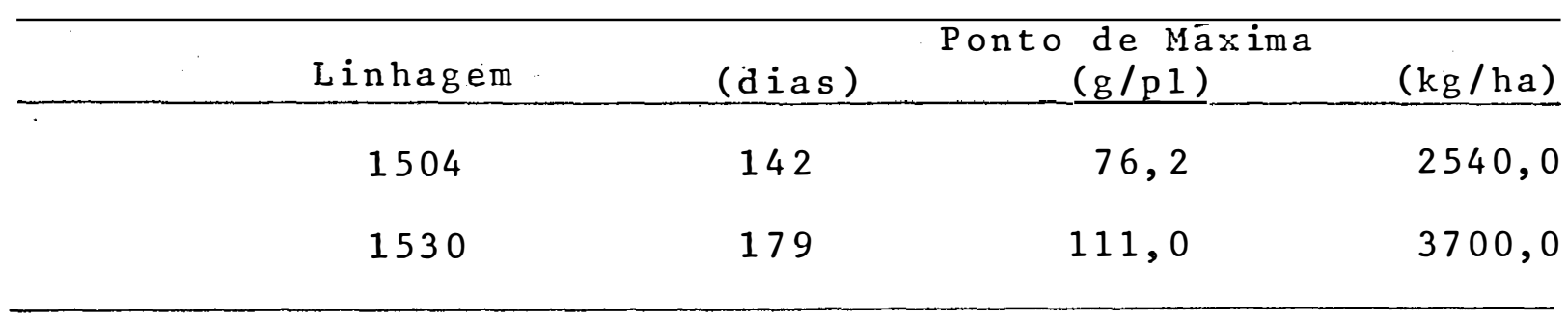


ficativa da primeira amostragem aos 50 dias. Essa diferença se faz sentir aos 106 dias, em pleno florescimento com maior acūmulo da matēria seca. Essa etapa é crítica, pois envolve o florescimento e a frutificação.

C ponto de máximo desenvolvimento estimado da planta e produção de matéria seca é atingido aos 142 e 179 dias, respectivamente, como se observa na Tabela b e Cráfico 1 para as linhagens 1504 e 1530 . Os valores encontrados são76,2, $111,0 \mathrm{~g} / \mathrm{planta,} 2.540$ e $3.700 \mathrm{~kg} / \mathrm{ha}$.

A partir dos 134 dias, no final do florescimento a linhagem 1504 diminui ligeiramente seu peso em matéria seca e a linhagem 1530 tem um ligeiro aumento na matéria seca que resulta grande diferença de crescimento entre as duas linhagens, na época da maturação de grãos aos 168 dias.

o acūmulo crescente de matéria seca total em $\mathrm{kg} / \mathrm{ha}$, em função da idade, também foi verificado por BRIouX (1923), LOUISE e PICARD (1891), PIERRE (1860), RADET (1955) e LEFẼVRE (1954)。

\subsection{Macronutrientes}

4.2.1. Nitrogênio

4.2.1.1. Concentração

A Tabela 7 mostra a concentração do nitrogênio 


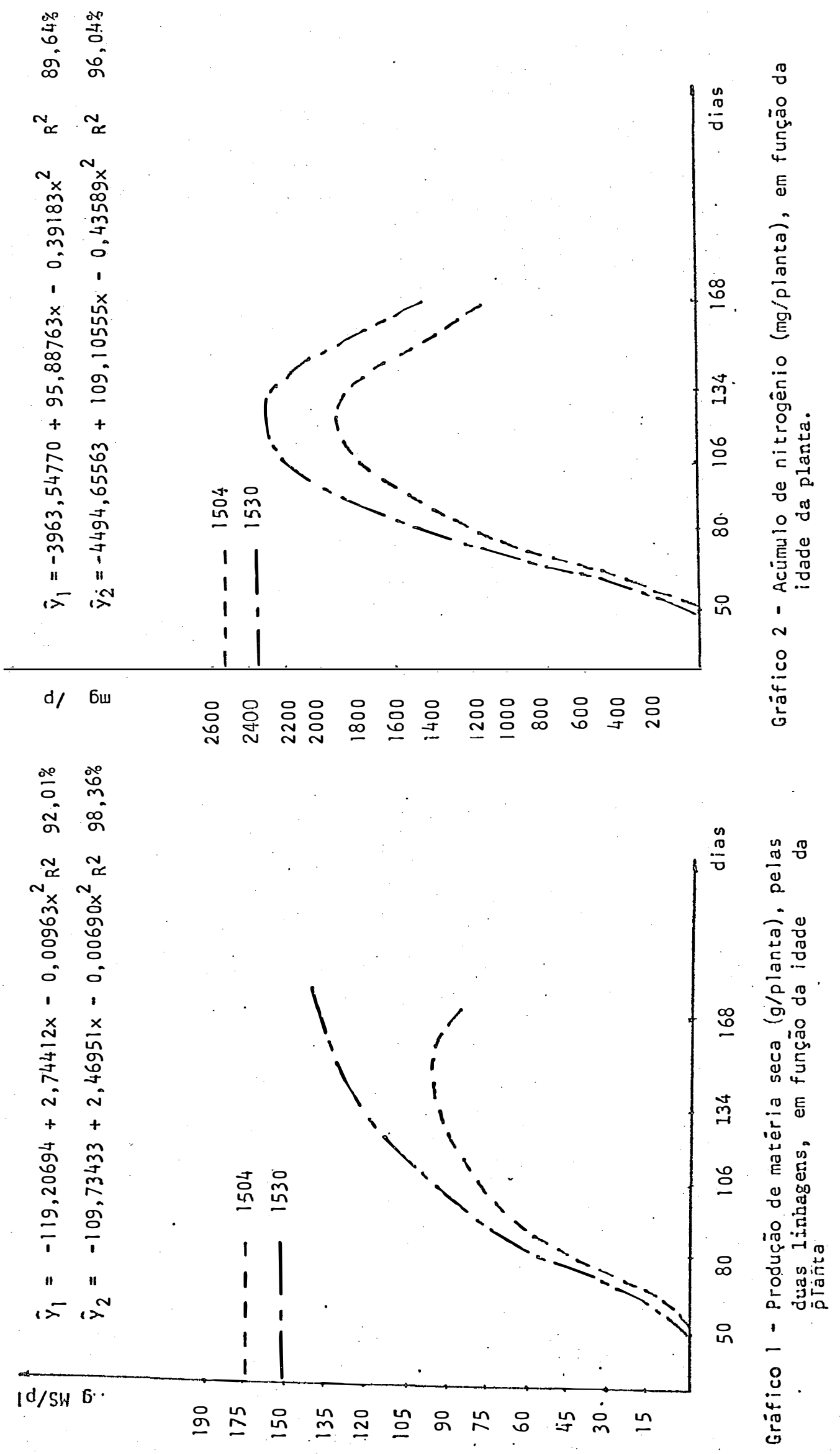


Tabela 7 - Concentração e acúmulos totais de nitrogênio pelas linhagens 1504 e 1530, em função da idade, em \% mg/ planta e kg/ha. (Mëdia de 4 repetições).

\begin{tabular}{ccccccc}
\hline $\begin{array}{c}\text { Dias após } \\
\text { emergência }\end{array}$ & \multicolumn{1}{c}{$\%$} & & $\mathrm{mg} / \mathrm{planta}$ & \multicolumn{2}{c}{$\mathrm{kg} / \mathrm{ha}$} \\
\hline & 1504 & 1530 & 1504 & 1530 & 1504 & 1530 \\
50 & 3,90 & 3,89 & $240,1 \mathrm{Da}$ & $260,4 \mathrm{Da}$ & 8,0 & 8,7 \\
80 & 3,33 & 3,35 & $775,5 \mathrm{CDa}$ & $1151,9 \mathrm{CDa}$ & 25,8 & 38,4 \\
106 & 2,98 & 2,85 & $2106,3 \mathrm{Aa}$ & $2231,7 \mathrm{ABa}$ & 70,2 & 74,4 \\
134 & 2,36 & 2,48 & $1866,9 \mathrm{ABa}$ & $2496,9 \mathrm{Aa}$ & 62,2 & 83,2 \\
168 & 1,53 & 1,31 & $1035,7 \mathrm{BCDa}$ & $1437,5 \mathrm{BCa}$ & 34,5 & 47,9
\end{tabular}

dms (Tukey) $5 \%=924,13$

C.V. $(\%)=34,40 \%$

* Médias seguidas de letras não comuns maiúsculas na coluna e minúsculas na linha, representam diferença significativa ao nivel de $5 \%$.

Tabela 8 - Resultados referentes a época de maior absorção e a quantidade máxima acumulada de nitrogênio, pelas linhagens 1504 e 1530 .

\begin{tabular}{cccc}
\hline Linhagem & \multicolumn{3}{c}{ Ponto de Máxima } \\
(dias $)$ & 122 & 1902,8 & 63,4 \\
1504 & 125 & 2332,7 & 77,7 \\
\hline
\end{tabular}


em diferentes épocas de amostragem. Quanto maior o crescimento da planta, menor a concentração do nutriente.

HAAG e MINAMI (1982) mostram a diminuição e o aumento da concentração do nitrogênio em couve-flor, cultivar Piracicaba precoce, de acordo com a época de colheita éórgão da planta.

ROLLIER (1970), na França, trabalhando com cultivar de outono, também encontrou menores concentrações com o crescimento da planta.

RACZ (1965) encontrou resultados decrescentes na concentração, de acordo com o aumento da matéria seca da planta, trabalhando com cultivar de verão.

4.2.1.2. Ac ūmu1o

Os resultados sobre o acūmulo de nitrogênio na planta toda estão expressos nas Tabelas 7 e 8 , para as duas linhagens, juntamente com a anālise estatistica. Não há diferença na quantidade de nitrogênio em todas as épocas de amostragem entre as duas 1 inhagens.

Evidencia-se através de diferença estatistica fases distintas de absorção, inerentes a diferentes épocas de amostragem. 
As duas linhagens têm baixa quantidade acumula da de nitrogênio até aos 80 dias, no início do florescimento. A partir desse estádio, o aumento é gradativo, com grande quantidade presente na planta aos 106 dias, em pleno florescimento. A linhagem 1504 tem seu máximo exigido aos 122 dias e a linhagem 1530, aos 125 dias, a partir da semeadura, no final do florescimento, de acordo com dados estimados.

De acordo com a Tabela 8 e Grä́fico 2 , as quantidades máximas estimadas encontradas foram de $1.902,8$ e $2.332,7$ mg/planta, 63,4 e 77,7 kg/ha, para as linhagens 1504 e 1530 .

o nitrogênio é o segundo nutriente mais exigido pela Colza, depois do potásio. A Tabela 27 expõe o fato, trazendo o acúmulo máximo de nitrogênio nas duas linhagens.

A couve-flor é uma hortaliça com exigência em nitrogênio maior que a colza, contendo ao final de seu ciclo, aos 96 dias a quantidade máxima de $2.760,6 \mathrm{mg} / \mathrm{planta}$ equivalen te a $68,0 \mathrm{~kg} / \mathrm{ha}$ do elemento. Para essa cultura, a sequência de aproveitamento do nitrogênio se faz de uma maneira diferente, com lento desenvolvimento e lenta exigência nutricional ate aos 36 dias, aumentando acentuadamente aos 76 dias na época da formação da "cabeça", por ėm, sem diminuição posterior, mas com aumento continuo de absorção até ofim do ciclo aos 96 dias (HAAG.e MINAMI, 1982 ).

E difícil comparar os dados de acúmulo de nitrogênio e outros nutrientes, em $\mathrm{kg} / \mathrm{ha}$, do experimento reali- 
zado no Brasil, com dados de experimentos feitos no exterior. Isso ocorre, devido ao fato do ciclo da cultura em outros pa I ses ser mais longo, chegando até 10 meses, enquanto no Brasil chega até 6 meses. A resposta dos nutrientes absorvidos muitas vezes é a mesma, havendo um aumento gradativo da quantida de presente na planta, atingindo-se um ponto de máximo acúmulo com posterior diminuição do nutriente absorvido. Porém, há uma defasagem no tempo.

Para BRIOUX (1923) o máximo contido estā entre 180 e 210 dias, no início do florescimento.

Para ROLlier (1969), PIERRE (1360), Radet(1952), citado por ROLLIER (197.0) e LEON (1978) esse máximo é atingido entre 210 e 240 dias, em pleno florescimento.

Para RACZ (1965) há absorção contínua do nitro gênio até o fim do ciclo.

De acordo com a Tabela 8, verifica-se que o má ximo do nitrogênio na planta ocorre próximo a 120 dias, no final do florescimento, com diminuição posterior. Isso equivale a uma menor quantidade de nitrogênio na planta, no presente trabalho, em relação a outros países.

\subsubsection{Fósforo}

\subsubsection{Concentração}

A concentração do fósforo é apontada na Tabe1a 9. I medida que são feitas as amostragens, os valores de 
Tabela 9 - Concentração e acūmulo totais de fósforo nelas li-nhagens, 1504 e 1530, em função da idade em \%, mg/ p.lanta e kg/ha (Média de 4 repetições).

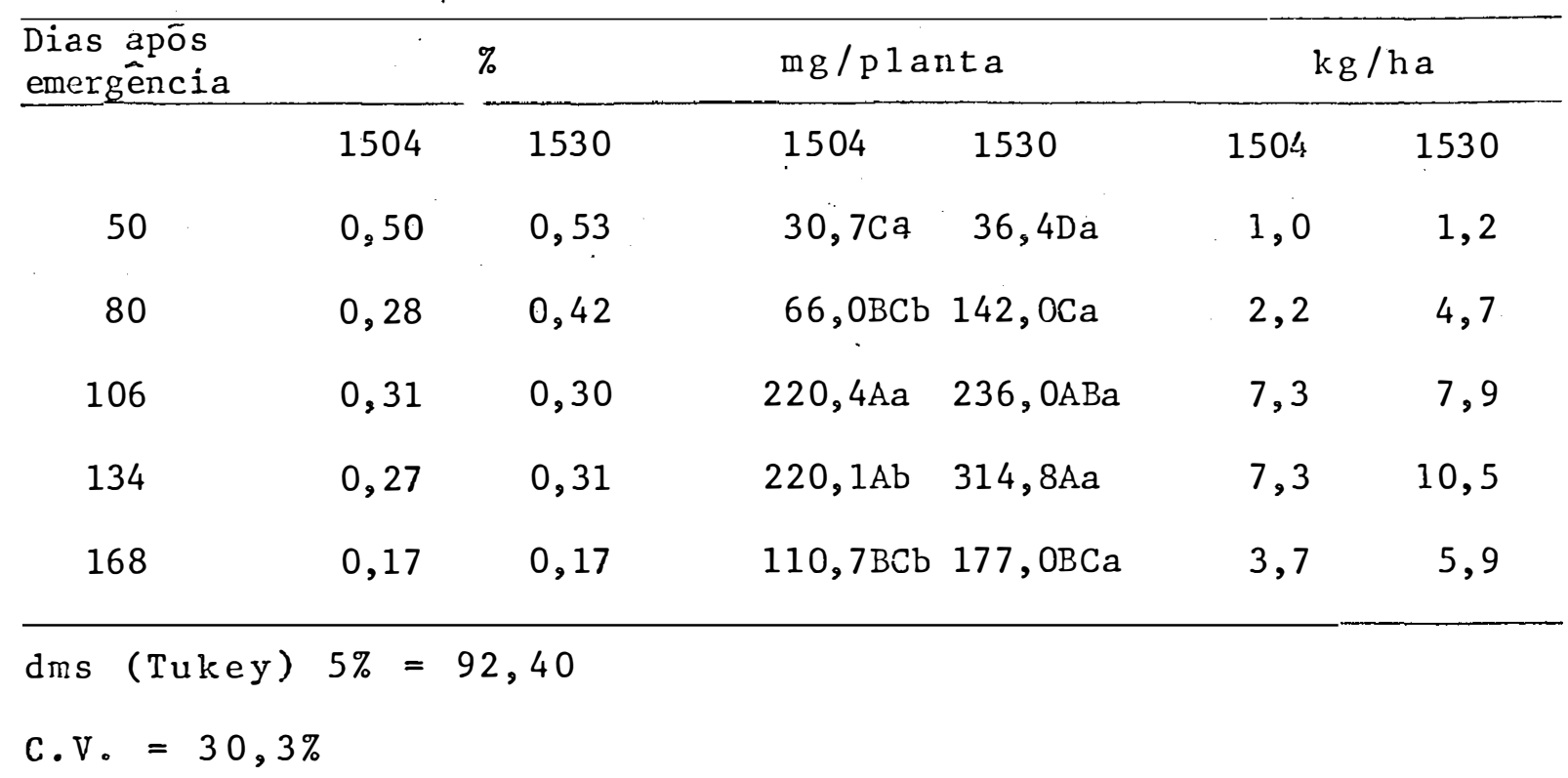

Tabela 10 - Resultados referentes à época de maior absorção e a quantidade máxima acumulada de fósforo, pelas linhagens 1504 e 1530 。

\begin{tabular}{cccc}
\hline Linhagem & (dias) & $\begin{array}{c}\text { Ponto de Maxima } \\
(\mathrm{mg} / \mathrm{p} 1)\end{array}$ & $(\mathrm{kg} / \mathrm{ha})$ \\
\hline 1504 & 124 & 205,1 & 6,8 \\
1530 & 127 & 274,3 & 9,1 \\
\hline
\end{tabular}


concentração diminuem, dado ao efeito de diluição do nutriente na planta, pelo aumento da matéria seca.

HAAG e MINAMI (1932) encontraram concentra-

ções variáveis de fósforo na couve-flor, cultivar Piracicaba precoce e repôlho, cultivar shikidore, de acordo com a época de colheita e órgão da planta.

SCHULTZ (1972), RACZ (1965) e ANDERSON et a $i$ i (1953), também constataram a mesma diminuição nas concentra ções de fósforo, com o tempo.

4.2.2.2. Acūmulo

os resultados sobre o acúmulo de fósforo pela planta toda estão nas Tabelas 9 e 10, juntamente com a aná1ise estatistica.

E notada maior exigência em fósforo da linhagem 1530 aos 30,134 e 168 dias de amostragens, havendo valores mais elevados desse elemento na planta nessas épocas.

A linhagem 1504 tem baixo acúmulo até aos 80 dias no início do florescimento, aumentando depois até aos 106 dias, em pleno florescimento, tendo alta exigência, nesse período. 0 máximo acumulado pela planta ocorre aos 124 dias, no fim do florescimento de acordo com os dados estimados.

A 1 inhagem 1530 tem baixo acúmulo até aos 
50 dias, no inỉcio do período vegetativo, aumentando depois até aos 80 dias, no início do florescimento, chegando nesse período a quantidades maiores significativamente em relação a outra linhagem demonstrando maior exigência desse nutriente.

Esse aumento continua até aos 106 dias, em pleno florescimento. 0 máximo exigido pela planta se dá aos 127 dias, no fim do florescimento de acordo com os dados estimados. As quantidades estimadas encontradas nesse período foram: 205,1, $274,3 \mathrm{mg} / \mathrm{p} 1 \mathrm{anta}, 6,8$ e 9,1 kg/ha para as 1 inhagens 1504 e 1530 . Isso é encontrado na Tabela 10 e Grä́fico 3.

o fósforó é o elemento menos exigido pela colza como nos mostra a Tabela 27 , para as duas 1 inhagens.

A quantidade de fósforo extraída pela couve flor, cultivar Piracicaba precoce, é maior (345,2 mg/planta e $8,6 \mathrm{~kg} / \mathrm{ha})$, aos 96 dias, no final no seu ciclo, bem como, pelo repôlho, cultivar shikidore, aos 105 dias (1.334,0 mg/ planta e $17,4 \mathrm{~kg} / \mathrm{ha})$. A couve-flor também tem o fósforo como o menos exigido dos macronutrientes, porém, o repolho o tem como o quarto nutriente mais exigido, depois do potássio, nitrogênio e cálcio, segundo HAAG e MINAMI (1982).

$$
\text { PIERRE (1860), LOUISE e PICARD (1891) e RACZ }
$$

(1965) encontraram absorção contĩnua até a maturação dos grãos. COURPRON et aZï·(1973) e LEFẼVRE (1957) acusam quantidades elevadas do elemento na planta até 9-10 me- 

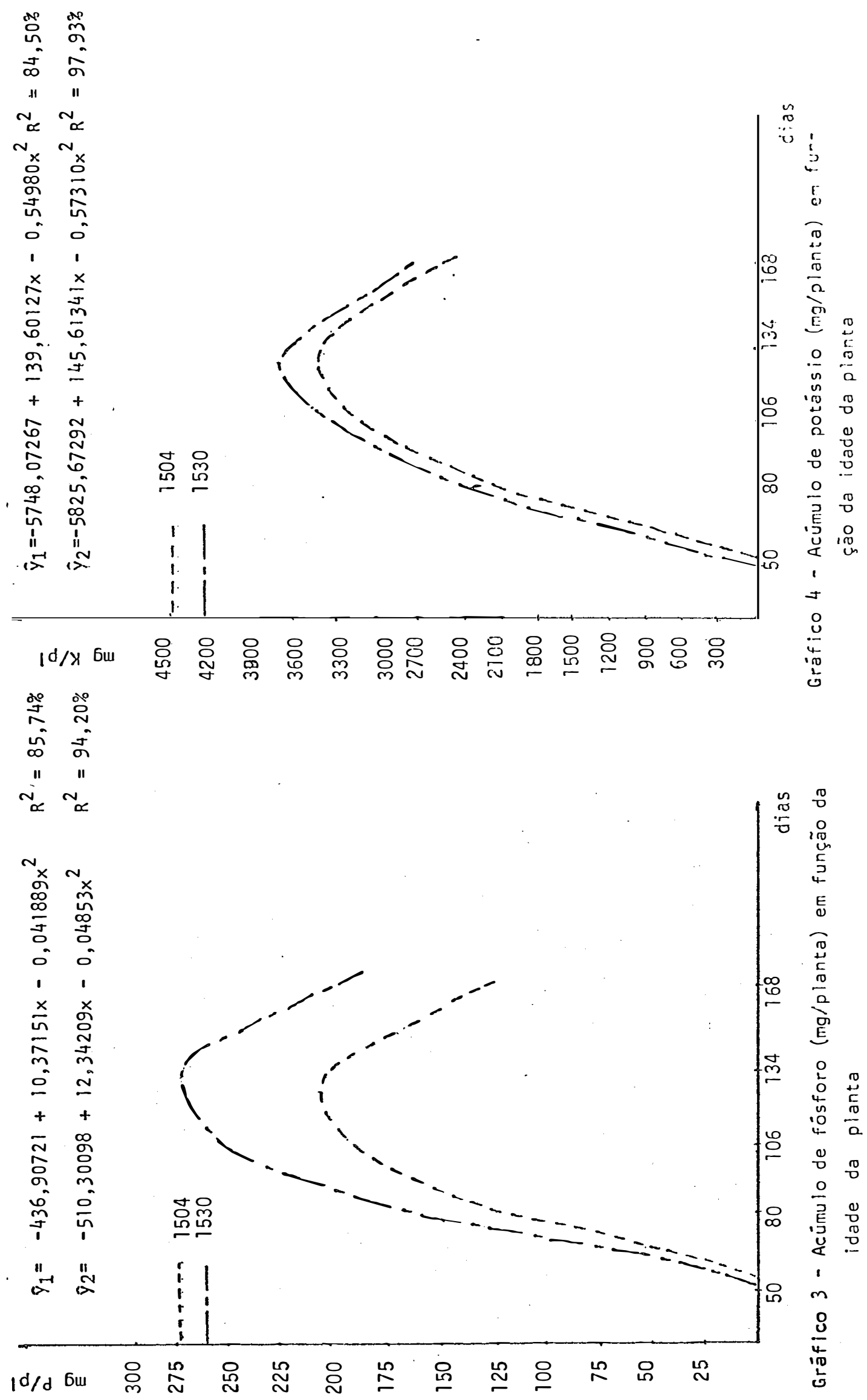
ses, no início da maturação, com diminuição posterior.

Esses dados discordam dos resultados encontra dos no presente trabalho。

4.2.3. Potássio

4.2.3.1. Concentração

A concentração do potássio na planta é menor com o seu crescimento e com o aumento da matéria seca produzida. Os dados são mostrados na Tabela 11 .

HAAG e MINAMI (1982) encontraram diferentes

concentrações em couve-flor, cultivar Piracicaba precoce e repôlho, cultivar Shikidore, de acordo com a época de co lheita e órgão da planta.

Dados aproximados são apresentados por SCHULTZ (1972), ROLLIER (1970) e LEFEVRE (1957) havendo concentração mais elevada no início do desenvolvimento da planta e menor no fim do seu desenvolvimento.

4.2.3.2. Acūmu 1 o

Não é notada diferença no acúmulo de potássio entre as duas linhagens, em todas as épocas de amostra- 
Tabela 11 - Concentração e acümulo totais de potássio pelas linhagens 1504 e 1530, em função da idade em \%, mg/planta e kg/ha (Média de 4 repetições).

\begin{tabular}{ccccccc}
\hline $\begin{array}{c}\text { Dias apos } \\
\text { emergencia }\end{array}$ & \multicolumn{2}{c}{$\%$} & \multicolumn{2}{c}{$\mathrm{mg} / \mathrm{pl}$} & \multicolumn{2}{c}{$\mathrm{kg} / \mathrm{ha}$} \\
\hline & 1504 & 1530 & 1504 & 1530 & 1504 & 1530 \\
50 & 6,50 & 7,31 & $393,0 \mathrm{Ca}$ & $494,9 \mathrm{Ba}$ & 13,1 & 16,5 \\
80 & 5,76 & 6,15 & $1310,2 \mathrm{BCa}$ & $2103,8 \mathrm{Aa}$ & 43,7 & 70,1 \\
106 & 5,28 & 4,34 & $3676,5 \mathrm{~A} \mathrm{a}$ & $3431,9 \mathrm{Aa}$ & 122,5 & 114,4 \\
134 & 3,32 & 3,10 & $2658,9 \mathrm{ABa}$ & $3125,2 \mathrm{Aa}$ & 88,6 & 104,2 \\
168 & 3,45 & 2,33 & $2264,7 \mathrm{Ba}$ & $2543,5 \mathrm{Aa}$ & 75,5 & 84,8 \\
\hline
\end{tabular}

dms (Tukey) $5 \%=1374,6$

C.V. $=31,75 \%$

Tabela 12 - Resultados referentes à época de maior absorção e a quantidade máxima acumulada de potássio, pelas linhagens 1504 e 1530 .

\begin{tabular}{rccc}
\hline Linhagem & Ponto de Mãxima & (dias) & $\begin{array}{c}\text { (mg/pl) } \\
\text { (mg/ha) }\end{array}$ \\
\hline 1504 & 127 & 3115,0 & 103,8 \\
1530 & 127 & 3423,6 & 114,1 \\
\hline
\end{tabular}


gem. A 1 inhagem 1504 apresenta baixo acúmulo de potássio até aos 80 dias, início do florescimento, aumentando até aos 106 dias, em pleno florescimento, com um máximo estimado nos teci dos aos 127 dias, no final do florescimento.

A 1 inhagem 1530 apresenta um aumento na quantidade de potássio acumulado a partir dos 50 dias, no início do desenvolvimento vegetativo, havendo exigência crescente atë os 106 dias, em pleno florescimento, chegando a um máximo estimado aos 127 dias, no fim do florescimento.

Esses resultados estão expressos nas Tabelas

11 e 12 .

Em mg/pl e kg/ha, os valores mäximos estimados acumulados são $3.115,0,3.423,6,103,8$ e 114,1 para as 1 inhagens 1504 e 1530, respectivamente, como nos expõe o Grāfico 4 .

o potássio é o nutriente mals extraído: pela colza, como nosassinala a Tabela 27 , para as duas linhagens.

Para HAAG e MINAMI (1982), a couve-flor, cultivar Piracicaba precoce e o repôlho, cultivar Shikidore também extraem maior quantidade do potássio em relação aos outros elementos. Na colza, o potássio é o nutriente mais extraỉdo, equivalente à quantidade extraída pela couve-flor e menor que a quantidade extraída pelo repôlho. Na couve - flor 
encontrou-se $3.067,7 \mathrm{mg} / \mathrm{planta}$ e $76,7 \mathrm{~kg} / \mathrm{ha}$ aos 96 dias, época de maior absorção. No repôlho, 6.142,0 mg/planta e $96,0 \mathrm{~kg} / \mathrm{ha}$ aos $105 \mathrm{dias}$.

Os dados obtidos são semelhante aos encontrados por Radet (1952), citado por ROLliER (1970) e RADET (1955). A absorção é contỉnua até 210 a 240 dias, em pleno florescimento, com diminuição posterior.

Porém, RACZ (1965) encontrou absorção contínua do potássio até o fim da maturação.

4.2.4. Cālcio

\subsubsection{Concentração}

A Tabela 13 apresenta a concentração do cálcio na planta toda, em diversas fases do ciclo da cultura. A con centração decresce com o aumento da matéria seca, sendo semelhante nas duas linhagens.

HAAG e MINAMI (1972) encontraram concentra ções diferentes, de acordo com o desenvolvimento da cultura e órgão analisado, podendo ser maior ou menor, quando trabalharam com couve-flor, cultivar Piracicaba precoce e repôlho, cultivar Shikidore. 
Tabela 13 - Concentração e acúmulo totais de Cálcio nas linha gens 1504 e 1530 em função da idade em \%, mg/ planta e kg/ha (Média de 4 repetições).

\begin{tabular}{ccccccc}
\hline $\begin{array}{c}\text { Dias apos } \\
\text { emergencia }\end{array}$ & & $\%$ & & \multicolumn{2}{c}{$\mathrm{mg} / \mathrm{pl}$} & \multicolumn{2}{c}{$\mathrm{kg} / \mathrm{ha}$} \\
\hline & 1504 & 1530 & 1504 & 1530 & 1504 & 1530 \\
50 & 2,72 & 2,46 & $167,6 \mathrm{Da}$ & $165,4 \mathrm{Ca}$ & 5,6 & 5,5 \\
80 & 1,71 & 1,79 & $390,7 \mathrm{CDa}$ & $612,3 \mathrm{BCa}$ & 13,0 & 20,4 \\
106 & 1,43 & 1,32 & $1013,6 \mathrm{Aa}$ & $1034,2 \mathrm{ABa}$ & 33,8 & 34,5 \\
134 & 1,15 & 1,10 & $906,4 \mathrm{ABa}$ & $1152,0 \mathrm{Aa}$ & 30,2 & 38,4 \\
168 & 0,82 & 0,81 & $527,3 \mathrm{BCDb}$ & $871,0 \mathrm{ABa}$ & 17,6 & 29,0
\end{tabular}

$\operatorname{dms}($ Tukey) $5 \%=486,0$

C.V. $=36,43 \%$

Tabela 14 - Resultados referentes à época de maior absorção e a quantidade máxima acumulada de cálcio, pelas linhagens 1504 e. 1530 .

\begin{tabular}{rcrr}
\hline Linhagem & (dias) & $\begin{array}{c}\text { Ponto de Máxima } \\
(\mathrm{mg} / \mathrm{pl})\end{array}$ & $(\mathrm{kg} / \mathrm{ha})$ \\
\hline 1504 & 123 & 925,7 & 30,8 \\
1530 & 131 & 1124,6 & 37,5 \\
\hline
\end{tabular}




$$
\text { LOUISE e PICARD (1891) e ANDERSON et a } i \text { i }
$$

(1958) também encontraram uma diminuição na concentração do cālcio, em relação às épocas de amostragem.

\subsubsection{Ac úmu 10}

As Tabelas 13 e 14 apresentam os dados acumu lados de cálcio na planta.

As 1 inhagens 1504 e 1530 diferem entre si em relação à quantidade de cálcio na planta, apenas na últị ma amostragem, onde o elemento se encontra em maior acúmulo na segunda linhagem.

o conteúdo do nutriente na linhagem 1504 é baixo. até aos $80 \mathrm{dias,}$ no início do florescimento aumentando a partir dai, sendo significativo aos 106 dias, em pleno florescimento e atingindo um máximo estimado aos 123 dias, no fim do florescimento.

A 1 inhagem 1530 tem baixo acūmulo atë aos 50 dias, inicio do desenvolvimento vegetativo, aumentando a partir daí, com alta quantidade absorvida aos 106 dias, pleno florescimento chegando a um máximo estimado aos 131 dias, no fim do florescimento.

As quantidades máximas de cálcio acumuladas 
na planta para as duas 1 inhagens são de $925,7,1.124,6 \mathrm{mg} /$ planta, 30,8 e $37,5 \mathrm{~kg} / \mathrm{ha}$, como se observa na Tabela 14 e Grä́fico 5 .

o cālcio é o terceiro nutriente mais exigido pela colza, como se observa na Tabela 27 , para as duas 1inhagens.

Para HAAG e MINAMI (1982) a couve-flor e o repôlho também acumulam cálcio, depois do nitrogênio e potássio. A quantidade encontrada na couve-flor, cultivar Piracicaba Precoce, é semelhante à quantidade encontrada na colza. o total acumulado na couve-flor após 96 dias, no fim do ciclo foi de $1.018,9 \mathrm{mg} / \mathrm{planta}$ e $25,48 \mathrm{~kg} / \mathrm{ha}$. O total acumulado pelo repôlho cultivar Shikidore após 105 dias, no final do seu ciclo foi de $2.189,0 \mathrm{mg} / \mathrm{planta}$ e 40,40 kg/ha, demonstrando ser este mais exigen te em cálcio que a couve-flor e a colza.

os dados de ANDERSON et alii (1958) concordam com os resultados encontrados no presente trabalho, havendo um máximo absorvido no fim do florescimento.

Os dados de ROLLIER (1970) são discordantes quanto à extração do nutriente, ocorrendo o ponto de máxima absorção, no inỉcio da maturação.

COURPRON et alii (1973) tambēm discordam ve- 

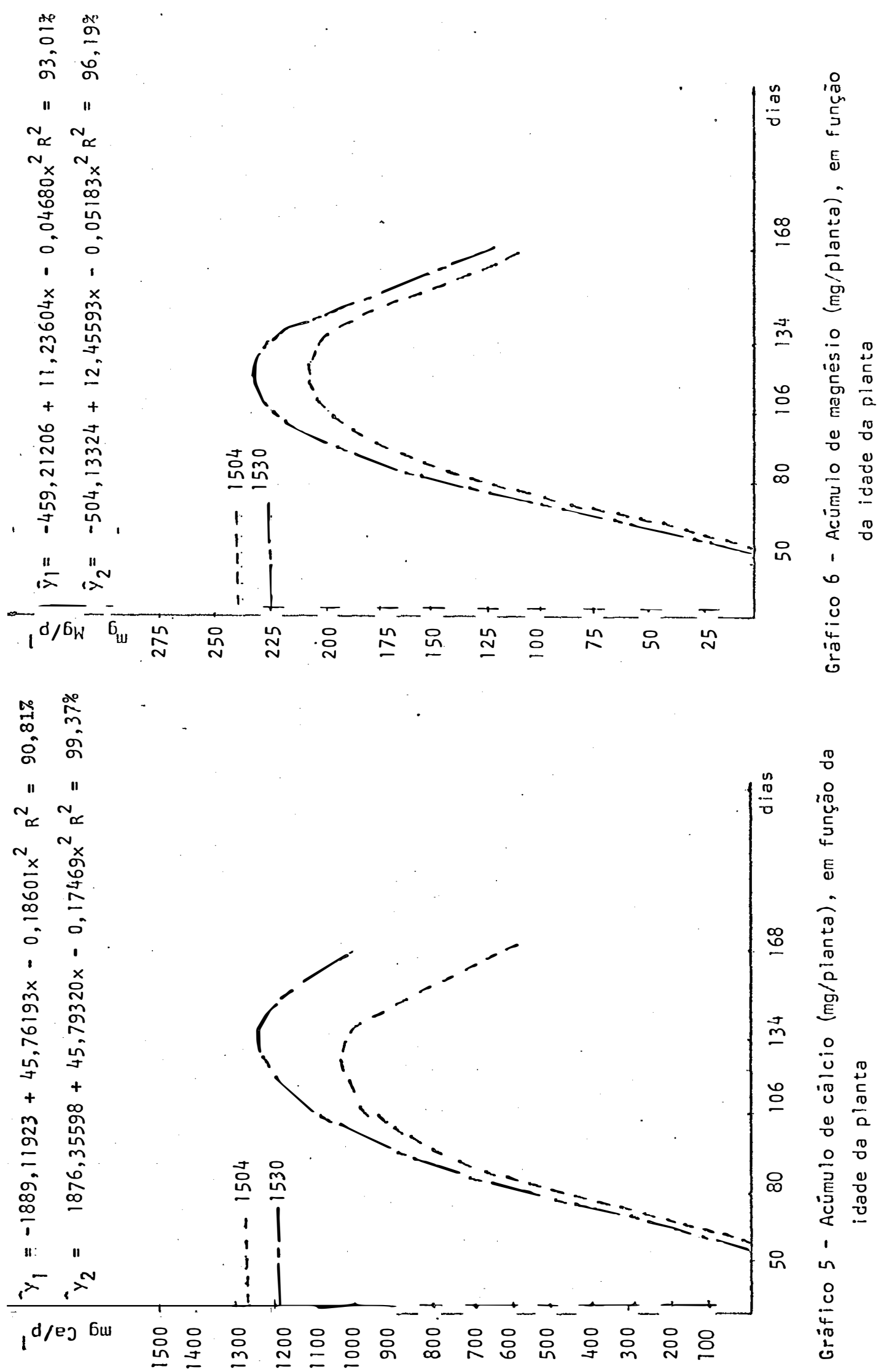
rificando absorção continua até pleno florescimento, com posterior diminuição, seguida de novo aumento na quantidade até o inỉcio da maturação.

\subsubsection{Magnésio}

4.2.5:1. Concentração.

Nota-se para as duas linhagens diminuição na concentração, com as épocas das amostragens. A Tabela 15 ex põe as diferentes concentrações do magnésio na planta.

Fenômeno idêntico é verificado por HAAG e MINAMI (1982) em couve-flor e repôlho, cultivar Piracicaba precoce e Shikidore.

Trabalhando com colza de inverno, ANDERSON et alii(1958)na Dinamarca, chegaram a respostas comuns encontrando diminuição do magnésio na planta com o aumento do seu desenvolvimento vegetativo. o mesmo foi verificado por schultz (1972), na Suécia, trabalhando com colza de outono.

4.2.5.2. Acūmulo

As quantidades de magnésio acumuladas pela planta podem ser vistas pelos dados das Tabelas 15 e 16.

Não hā diferença no acūmulo do nutriente en- 
Tabela 15 - Concentração e acūmulo totais de Magnésio nas 1 inhagens 1504 e 1530, em função da idade em \%, mg/ planta e kg/ha (Média de 4 repetiçöes).

\begin{tabular}{ccccccc}
\hline $\begin{array}{c}\text { Dias após } \\
\text { emergência }\end{array}$ & \multicolumn{2}{c}{$\%$} & \multicolumn{2}{c}{$\mathrm{mg} / \mathrm{pl}$} & \multicolumn{2}{c}{$\mathrm{kg} / \mathrm{ha}$} \\
\hline & 1504 & 1530 & 1504 & 1530 & 1504 & 1530 \\
50 & 0,65 & 0,65 & $40,2 \mathrm{Ca}$ & $44,4 \mathrm{Da}$ & 1,3 & 1,5 \\
80 & 0,44 & 0,41 & $100,6 \mathrm{BCa}$ & $141,1 \mathrm{BCa}$ & 3,3 & 4,7 \\
506 & 0,33 & 0,28 & $231,1 \mathrm{Aa}$ & $224,1 \mathrm{ABa}$ & 7,7 & 7,5 \\
134 & 0,26 & 0,25 & $211,9 \mathrm{Aa}$ & $263,9 \mathrm{Aa}$ & 7,1 & 8,8 \\
168 & 0,15 & 0,10 & $101,3 \mathrm{BCa}$ & $113,8 \mathrm{CDa}$ & 3,4 & 3,8 \\
\hline
\end{tabular}

dms (Tukey) $5 \%=93,6$

C.V. $=32,89 \%$

Tabela 16 - Resultados referentes à época de maior absorção e a quantidade máxima acumulada de magnésio, pelas 1 inhagens 1504 e 1530 .

\begin{tabular}{cccc}
\hline Linhagem & (dias) & $\begin{array}{c}\text { Ponto de Mãxima } \\
\text { (mg/pl) }\end{array}$ & (kg/ha) \\
\hline 1504 & 120 & 215,1 & 7,2 \\
1530 & 120 & 244,1 & 8,1 \\
\hline
\end{tabular}


tre as duas 1 inhagens em qualquer época amostrada.

Encontrou-se baixo conteūdo do nutriente até aos 80 dias, início do florescimento na linhagem 1504, aumentando a partir dessa fase, chegando a quantidades maiores aos 106 dias, em pleno florescimento.

o máximo estimado de magnésio acumulado na plan ta coda $\vec{e}$ atingido aos 120 dias, no fim do florescimento.

Baixo acūmulo de magnésio é encontrado até aos 50 dias, na 1 inhagem 1530, aumentando a partir desse estádio, chegando aos 106 dias, em pleno florescimento com resultado diferente significativamente dos estädios anteriores. As quantidades máximas estimadas acumuladas aos 120 dias, para as 1 inhagens 1504 e 1530 são de $215,1,244,1 \mathrm{mg} / \mathrm{p} 1,7,2$ e $8,1 \mathrm{~kg} / \mathrm{ha}$. O Gräfico 6 ilustra o fenômeno.

o magnésio é um nutriente pouco acumulado pela colza, estando em ültimo lugar, na preferência de absorção, juntamente com o fósforo. Isso é visto na Tabela 27.

Comparativamente, a absorção do magnésio pela couve-flor e repôlho é encontrada em HAAG e MINAMI (1982), trabalhando com cv. Piracicaba Precoce e Shikidore. 0 compor tamento da couve-flor na exigência do magnésio, é o mesmo da colza. O nutriente é tão pouco acumulado, quando o fósforo.

As quantidades de magnésio encontradas no fim 
do ciclo da couve-flor, aos 96 dias são de $438,9 \mathrm{mg} / \mathrm{planta}$ e $10,9 \mathrm{~kg} / \mathrm{ha}$.

A exigência do repôlho é bastante baixa tam bém sendo o nutriente menos encontrado, após todo o seu ciclo, junto com o enxôfre. Porém, as duas hortaliças são mais exigentes em magnésio em relação à colza.

As quantidades encontradas são $474,0 \mathrm{mg} / \mathrm{plan-}$ ta e $9,9 \mathrm{~kg} / \mathrm{ha}$.

Os dados concordam com ANDERSON et a $i$ i (1958) havendo acúmulo crescente do magnésio até o final do florescimento.

A absorção do elemento é contínua e crescente até o fim da maturação dos grãos, segundo LOUISE e PICARD (1891) e RADET (1956).

\subsubsection{Enxôfre}

\subsubsection{Concentração}

A Tabela 17 apresenta a concentração de enxôfre na planta. Há uma aparente diminuição da concentração do nutriente, com o tempo. Isso pode ser explicado pelo efeito de diluição, relativo ao constante crescimento da planta e aumento da matéria seca. 
Tabela 17 - Concentração e acúmulo totais de Enxôfre nos linhagens 1504 e 1530, em função da idade, em \%, mg/planta e kg/ha (Média de 4 repetiçōes).

\begin{tabular}{ccccccc}
\hline $\begin{array}{c}\text { Dias apōs } \\
\text { emergência }\end{array}$ & \multicolumn{2}{c}{$\%$} & \multicolumn{2}{c}{$\mathrm{mg} / \mathrm{pl}$} & \multicolumn{2}{c}{$\mathrm{kg} / \mathrm{ha}$} \\
\hline 50 & 1504 & 1530 & 1504 & 1530 & 1504 & 1530 \\
80 & 0,83 & 0,83 & $50,8 \mathrm{Ca}$ & $56,1 \mathrm{Ba}$ & 1,7 & 1,8 \\
106 & 0,71 & 0,77 & $160,4 \mathrm{BCa}$ & $265,6 \mathrm{Aa}$ & 5,3 & 8,8 \\
134 & 0,54 & 0,44 & $377,2 \mathrm{Aa}$ & $346,8 \mathrm{Aa}$ & 12,6 & 11,5 \\
168 & 0,37 & 0,39 & $304,2 \mathrm{ABa}$ & $399,1 \mathrm{Aa}$ & 10,1 & 13,3 \\
& 0,31 & 0,29 & $200,8 \mathrm{BCb}$ & $311,5 \mathrm{Aa}$ & 6,7 & 10,4
\end{tabular}

dms (Tukey) $\%=152,07$

C. V. $=31,35 \%$

Tabela 18 - Resultados referentes à época de maior absorção e a quantidade máxima acumulada de enxôfre, pelas linhagens 1504 e 1530 .

\begin{tabular}{cccc}
\hline Linhagem & (dias) & $\begin{array}{c}\text { Ponto de Mãxima } \\
\text { (mg/p 1) }\end{array}$ & (kg/ha) \\
\hline 1504 & 122 & 335,6 & 11,2 \\
1530 & 130 & 398,5 & 13,3 \\
\hline
\end{tabular}


o mesmo se verificou com outras culturas como aponta HAAG e MINAMI (1982), em couve-flor, cultivar Piracicaba precoce e: repôlho, cultivar Shikodore. As concentrações variam com as partes da planta e épocás de amostragem.

Radet (1955) e Walker et alii (1954), cita dos por Holmes (1980), encontraram o mesmo resultado.

4.2.6.2. Acūmu 10

Atravës do exame das Tabelas 17 e 18, podese saber as quantidades necessārias de enxôfre, para a col$z a$, em diversas fases do seu desenvolvimento.

A diferença entre as duas linhagens se faz apenas na ültima amostragem, onde se encontra maior valor de enxôfre acumulado na. 1inhagem 1530 .

A linhagem 1504 tem baixo acúmulo de enxôfre até aos 80 dias do seu desenvolvimento, no início do florescí mento, chegando a quantidades maiores aos 106 dias, em pleno florescimento, com um máximo estimado aos 122 dias, no final do florescimento. A partir dessa fase há menor quantidade encontrada do nutriente, pela senescência e queda das folhas. 
A 1 inhagem 1530 apresenta baixo conteúdo do elemento até aos 50 dias no período vegetativo e alta quantidade absorvida aos 106 dias, em plenoflorescimento, chegando a um máximo estimado aos 130 dias, no final do florescimento.

As linhagens 1504 e 1530 tiveram por estimativa no período máximo de acúmulo 335,6 e 398,5 mg/planta e 11,2 e $13,3 \mathrm{~kg} / \mathrm{ha}$ de enxôfre. O Grä́fico 7 ilustra o fato.

o enxôfre è ò quarto nutriente mais absorvido pela colza, sendo assim encontrado na Tabela 27.

A extração pela couve-flor cv. Piracicaba Precoce aos 96 dias é de $839,4 \mathrm{mg} / \mathrm{p} 1$ anta e $20,9 \mathrm{~kg} / \mathrm{ha}$, enquanto o repôlho cv. Shikidore aos 105 dias retira $806,0 \mathrm{mg} / \mathrm{p} 1 \mathrm{anta}$ e $16,8 \mathrm{~kg} / \mathrm{ha}$. Ambos são mais exigentes no nutriente que a co 1 $\mathrm{za}$.

o comportamento da couve-flor é o mesmo que a colza, do ponto de vista de preferência de absorção, estando o enxôfre em quarto lugrar, enquanto que o repôlho absorve menos enxôfre, em quantidades equivalentes ao magnésio (HAAG e MINAMI, 1982).

Resultados bem diferentes são apontados por COURPROiv et alii (1973) e ROLLIER (1969). As quantidades acumuladas apresentam um máximo no início da maturação. 


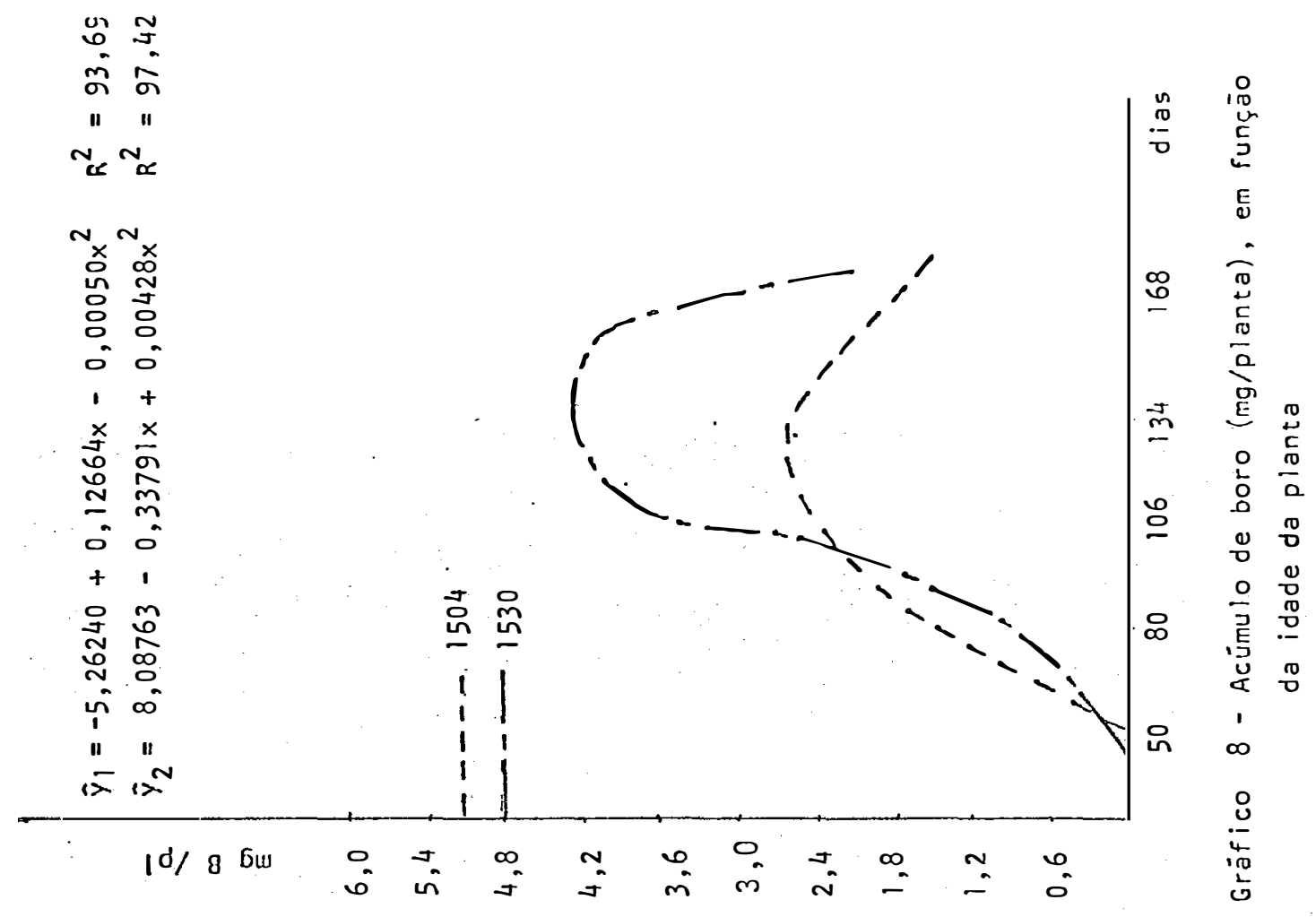

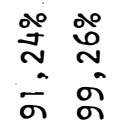

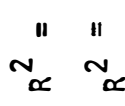

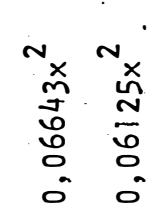

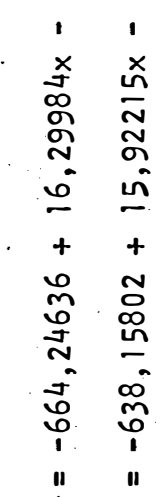

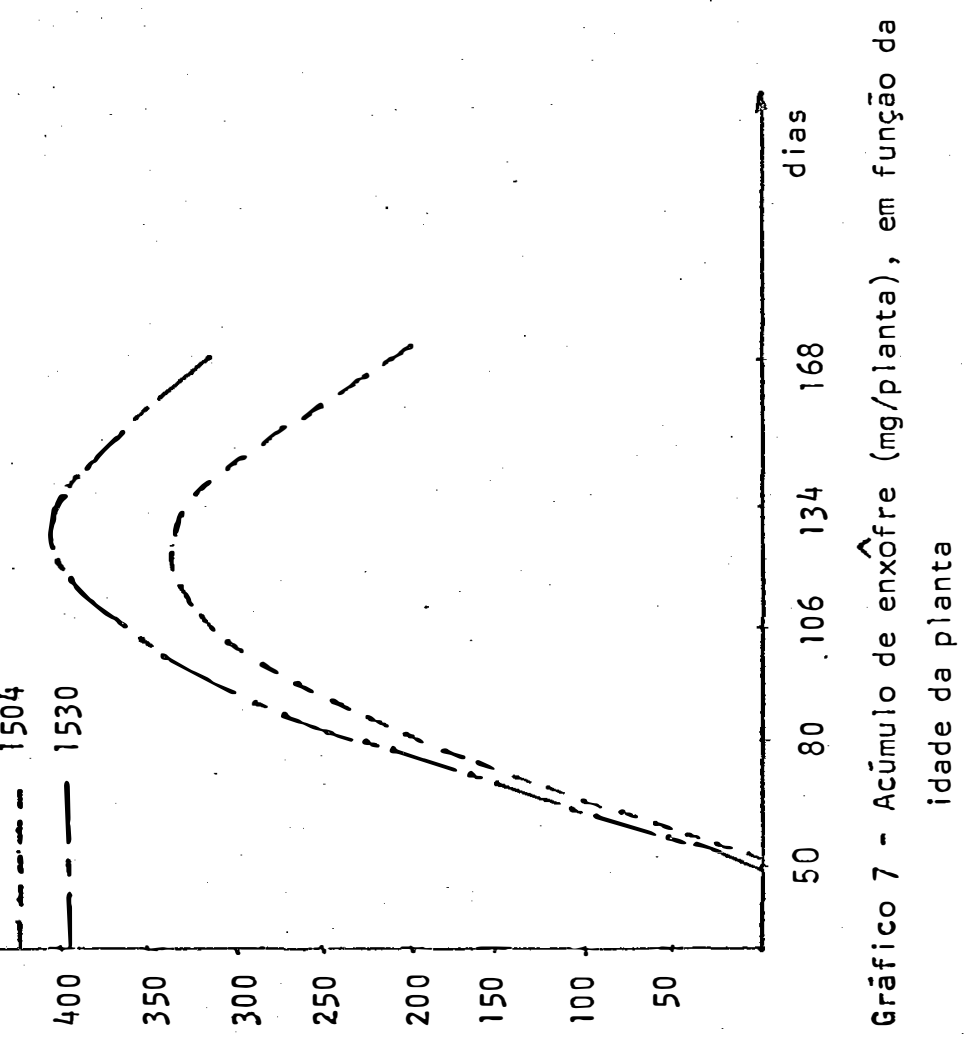


Há maiores diferenças nos dados de STUDER (1969) e BRIOUX (1923), onde a extração se faz de uma maneira contínua até a colheita.

\title{
4.3. Micronutrientes
}

4.3.1. Boro

\author{
$4 \cdot 3 \cdot 1 \cdot 1$. Concentração \\ Os micronutrientes apresentam-se em menores
}

concentrações à medida que a planta se desenvolve. A concentração de boro é encontrada na Tabela 19.

A literatura referente à concentração de micro nutrientes é escassa, havendo apenas alguns trabalhos que podem servir de comparação ao presente ensaio.

MIKOS (1.976) encontrou, na ültima amostragem, uma concentração média de" boro de 13,0 ppm considerando raíz, caule, folhas, flores, vagens e sementes, menor que a concen tração encontrada no trabalho em questão na mesma época de amostragem.

$4 \cdot 3 \cdot 1 \cdot 2 \cdot$ Ac ūmulo

As Tabelas 19 e 20 mostram o acúmulo de boro, 
Tabela 19 - Concentração e acümulo totais de Boro nas linha-. gens 1504 e 1530, em ppm, mg/p1 e g/ha em função de épocas progressivas de colheita (Média de 4 repetições ).

\begin{tabular}{ccccccc}
\hline $\begin{array}{c}\text { Dias após } \\
\text { emergência }\end{array}$ & \multicolumn{2}{c}{$\mathrm{p} \mathrm{pm}$} & \multicolumn{2}{c}{$\mathrm{mg} / \mathrm{pl}$} & \multicolumn{2}{c}{$\mathrm{g} / \mathrm{ha}$} \\
\hline & 1504 & 1530 & 1504 & 1530 & 1504 & 1530 \\
50 & 62,00 & 73,75 & $0,38 \mathrm{Ca}$ & $0,47 \mathrm{Ca}$ & 12,8 & 15,7 \\
80 & 38,31 & 35,64 & $1,17 \mathrm{BCa}$ & $1,20 \mathrm{BCa}$ & 39,0 & 40,0 \\
106 & 39,34 & 31,56 & $2,71 \mathrm{Aa}$ & $2,46 \mathrm{Ba}$ & 90,3 & 82,0 \\
134 & 35,25 & 44,10 & $2,85 \mathrm{Aa}$ & $4,50 \mathrm{Aa}$ & 95,0 & 150,0 \\
168 & 25,50 & 21,02 & $1,69 \mathrm{ABCb}$ & $2,29 \mathrm{Ba}$ & 56,3 & 76,3 \\
\hline
\end{tabular}

dms (Tukey) $5 \%=1,33$

C.V. $=34,40 \%$ 


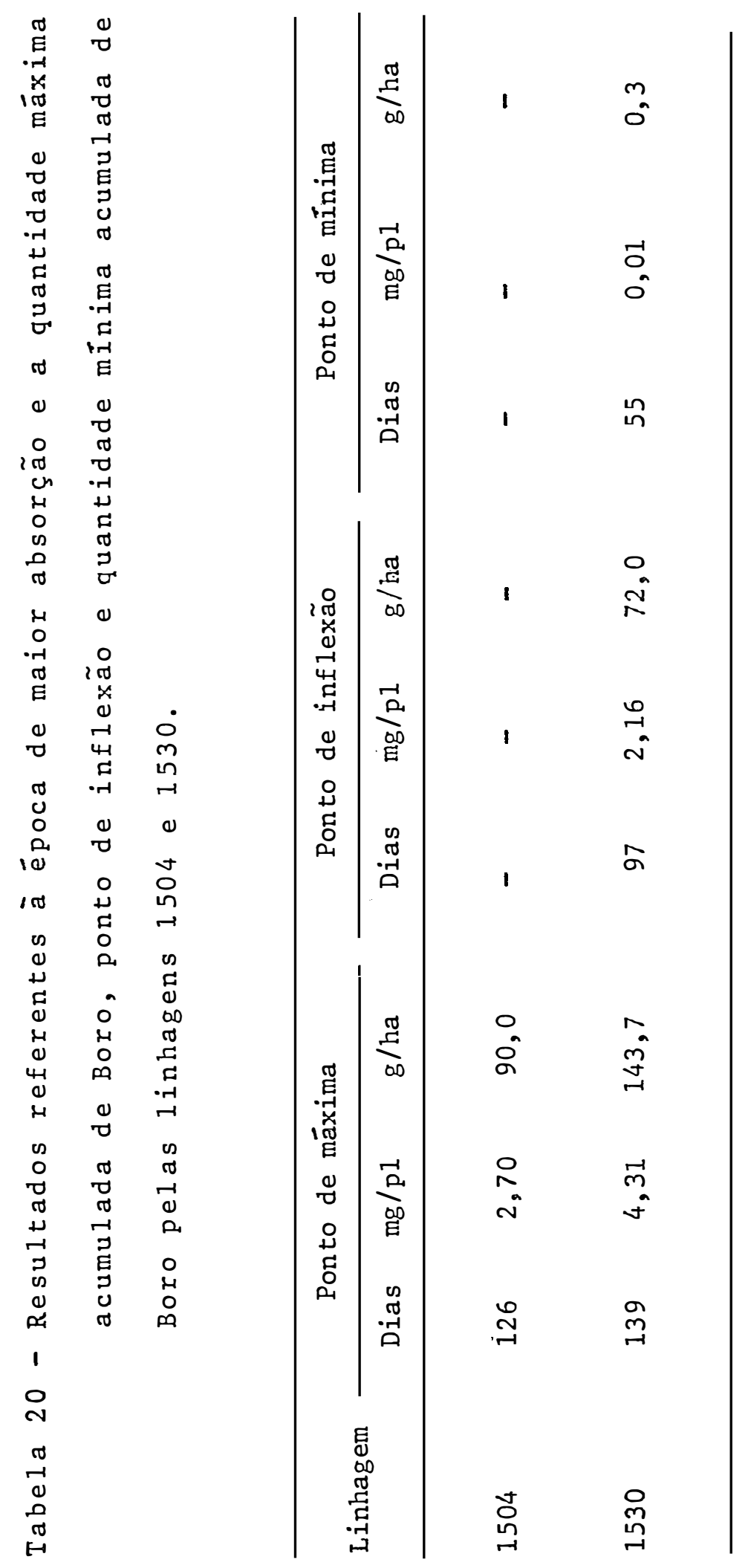


em mg/planta e g/ha, com a referente anālise estatística.

Existe diferença entre as duas 1 inhagens apenas aos 168 dias, na maturação dos grãos, com maior acūmulo de boro pela 1 inhagem 1530 .

A. 1 inhagem 1504 requer pouco boro até aos 80 dias, no início do florescimento, aumentando a exigência aos 106 dias, em pleno florescimento, com um máximo estimado aos 126 dias, no fim do florescimento. Nota-se na linhagem 1530 baixa absorção até aos 50 dias, no período vegetativo, aumentando após esse período, até aos 106 dias, em plenoflorescimento, com exigência máxima estimada aos 136 dias, no fim do florescimento.

Atravēs da Tabela 20 e Grä́ico 8, se tem o ponto de inflexão, para a 1 inhagem 1530 , atingido aos 97 dias, com 2,16 mg/planta e 72,0. g/ha de boro acumulado. 0 ponto de mínimo ocorre aos $55 \mathrm{dias,} \mathrm{com} \mathrm{0,01} \mathrm{mg/planta} \mathrm{e}$ 0,3 g/ha do elemento requerido para a mesma linhagem. Os pontos de máxima exigência estimada que aparecem nas duas 1inhagens, chegam a 2,70, 4,31 mg/p1anta, 90,0 e 143,7 g/ha aos 106 e 139 dias .

o boro é o terceiro micronutriente mais

do pela colza, depois do ferro e manganês. A Tabela 27 assinala o exposto.

Procurando determinar a extração de micronu 
trientes em hortaliças folhosas, HAAG et alii (1982), trabalhando com couve-flor cv. Piracicaba Precoce e repôlho cv. Shi kidore, em análise da cabeça e planta inteira encontraram 74,0 g/ha de bo ro na couve-flor, no fim do seu crescimento. Através desse dado sabe-se que a couve-flor extrai mencr quantidade desse nutriente em relação a colza.

4.3.2. Cobre

\subsubsection{Concentração}

A Tabela 21 expõe os resultados das concentrações de cobre na colza nos diversos estádios de desenvolvi mento. Os dados decrescem de acordo com as seguintes amostra gens.

MIKOS (197.6) e GLINSKI et alii (1973), na Polônia, encontraram quantidades médias do nutriente de 5,1 e 7,4 ppm, respectivamente, no fim do ciclo da cultura, ligeiramente maiores que a ūltima amostragem da colza.

$4 \cdot 3 \cdot 2 \cdot 2$. Acūmulo

As quantidades de cobre acumulado são mostradas nas Tabelas 21 e 22 .

As duas linhagens absorvem pequena quantidade 
Tabela 21. - Concentração e acúmulo totais de Cobre nas linhagens 1504 e 1530, em ppm, mg/pl e g/ha, em função de épocas progressivas de colheita (Média de 4 repetições).

\begin{tabular}{ccccccc}
\hline $\begin{array}{c}\text { Dias apōs } \\
\text { emergência }\end{array}$ & \multicolumn{2}{c}{$\mathrm{ppm}$} & \multicolumn{2}{c}{$\mathrm{mg} / \mathrm{p} 1$} & \multicolumn{2}{c}{$\mathrm{g} / \mathrm{ha}$} \\
\hline & 1504 & 1530 & 1504 & 1530 & 1504 & 1530 \\
50 & 9,50 & 9,25 & $0,06 \mathrm{Ca}$ & $0,06 \mathrm{Ba}$ & 1,9 & 2,1 \\
80 & 5,39 & 5,27 & $0,12 \mathrm{BCa}$ & $0,19 \mathrm{Ba}$ & 4,0 & 6,3 \\
106 & 6,38 & 4,80 & $0,45 \mathrm{Aa}$ & $0,38 \mathrm{Aa}$ & 15,0 & 12,7 \\
134 & 5,14 & 4,79 & $0,40 \mathrm{Aa}$ & $0,49 \mathrm{Aa}$ & 13,3 & 16,3 \\
168 & 4,10 & 4,72 & $0,27 \mathrm{ABb}$ & $0,49 \mathrm{Aa}$ & 9,0 & 16,3 \\
\hline
\end{tabular}

$\mathrm{dms}$ (Tukey) $5 \%=0,19$

C.V. $=33,02 \%$

Tabela 22 - Resultados referentes à época de maior absorção e a quantidade máxima acumulada de cobre pelas linhagens 1504 e 1530

\begin{tabular}{cccc}
\hline Linhagem & (dias) & Ponto de Máxima & $(\mathrm{g} / \mathrm{ha})$ \\
\hline 1504 & 128 & 0,40 & 13,3 \\
1530 & 164 & 0,50 & 16,7 \\
\hline
\end{tabular}


do nutriente até aos 80 dias, no início do florescimento, com aumento significativo aos 106 dias, em pleno florescimen to e um máximo estimado de cobre na planta alcançado aos 128 dias, no fim do florescimento, na linhagem 1504 e aos 164 dias, no início da maiuração na 1 inhagem 1530 .

o máximo acumulado, ilustrado na Tabela 22 e Gräfico 9 é de $0,40,0,50 \mathrm{mg} / \mathrm{planta,} \mathrm{correspondendo} \mathrm{a} 13,3$ e $16,7 \mathrm{~g} / \mathrm{ha}$.

o cobre é o micronutriente menos exigido pela colza, demonstrado na Tabela 27 .

o elemento também foi estudado por HAAG et alii (1982), em couve-flor, cultivar Piracicaba precoce e re $\hat{\imath}$ polho, cultivar shikidore. As quantidades acumuladas são em $\mathrm{g} / \mathrm{ha}$ de 17,0 e 44,1 para as duas 1 inhagens, sendo mais exigentes que a colza nesse nutriente. o repôlho é considera do uma cultura bastante exigente em cobre.

\subsubsection{Ferro}

\subsubsection{Concentração}

A Tabela 23 apresenta as concentrações de ferro Observa-se que até aos 80 dias há diminuição do ferro na plan 

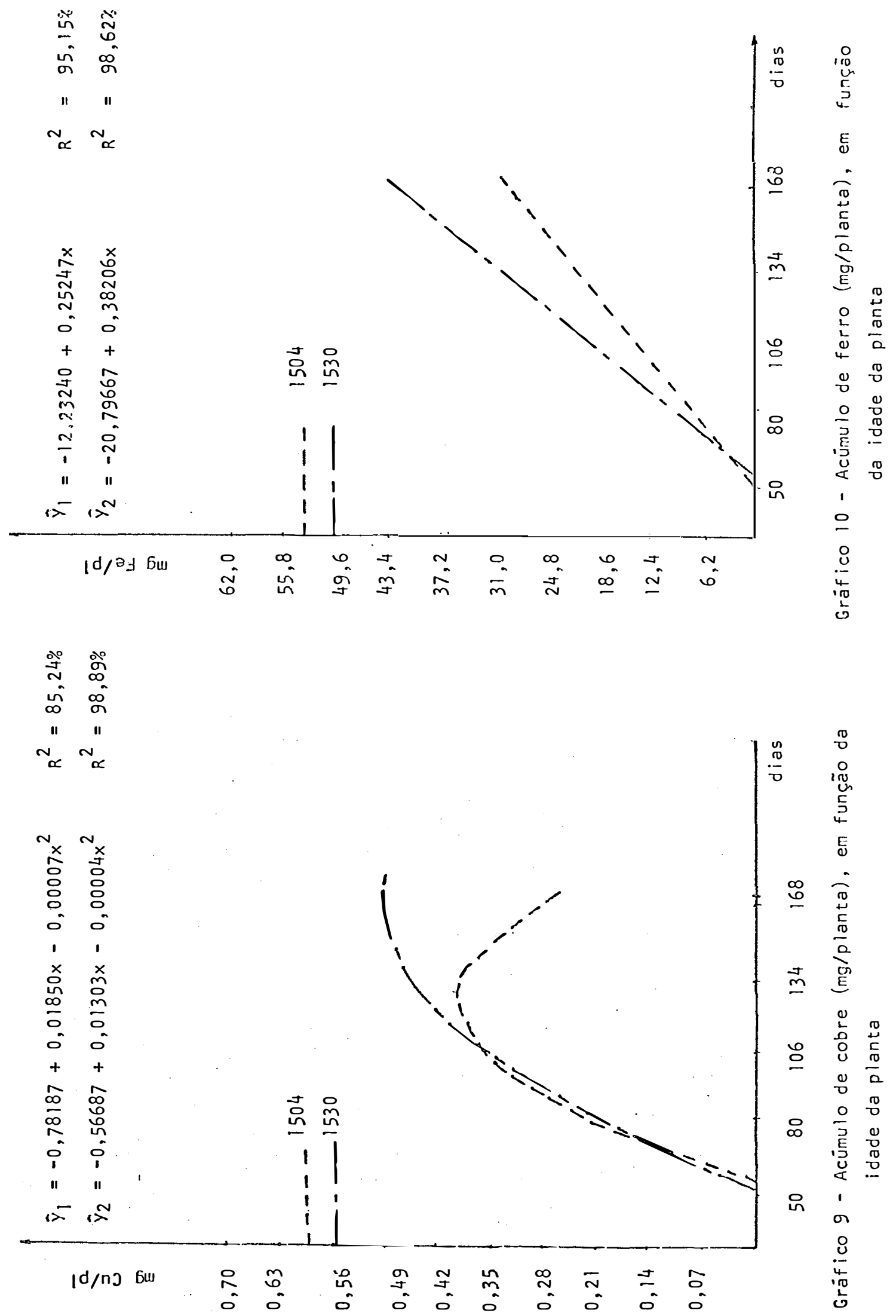
Tabela 23 - Concentração e acümulo totais de Ferro nas linhagens 1504 e 1530, em ppm, mg/ple g/ha em função de épocas progressivas de colheita (Média de 4 repetições)

\begin{tabular}{ccccccc}
\hline $\begin{array}{c}\text { Dias apos } \\
\text { emergencia }\end{array}$ & \multicolumn{2}{c}{$\mathrm{ppm}$} & \multicolumn{2}{c}{$\mathrm{mg} / \mathrm{pl}$} & \multicolumn{2}{c}{$\mathrm{g} / \mathrm{ha}$} \\
\hline & 1504 & 1530 & 1504 & 1530 & 1504 & 1530 \\
50 & 871,25 & 527,25 & $5,31 \mathrm{Ca}$ & $3,53 \mathrm{Da}$ & 177,0 & 117,6 \\
80 & 229,20 & 222,18 & $5,31 \mathrm{BC}$ a & $7,64 \mathrm{CDa}$ & 177,0 & 254,7 \\
106 & 252,67 & 231,67 & $18,48 \mathrm{ABCa} .18,05 \mathrm{BCDa}$ & 616,0 & 601,7 \\
134 & 289,64 & 347,89 & $22,57 \mathrm{ABCa} 33,00 \mathrm{ABa}$ & 752,3 & 1100,0 \\
168 & 431,57 & 408,21 & $28,29 \mathrm{Ab}$ & $42,86 \mathrm{Aa}$ & 943,0 & 1428,6
\end{tabular}

dms (Tukey) $5 \%=17,39$

C. V. $=48,13 \%$

Tabela 24 - Concentração e acúmulo totais de Manganês na plan ta em ppm, mg/planta e g/ha, para as linhagens 1504 e 1530 (Média de 4 repetições).

\begin{tabular}{ccccccc}
\hline $\begin{array}{c}\text { Dias após } \\
\text { emergência }\end{array}$ & \multicolumn{2}{c}{$\mathrm{p} \mathrm{pm}$} & \multicolumn{2}{c}{$\mathrm{mg} / \mathrm{pl}$} & \multicolumn{2}{c}{$\mathrm{g} / \mathrm{ha}$} \\
\hline & 1504 & 1530 & 1504 & 1530 & 1504 & 1530 \\
50 & 57,75 & 51,25 & $0,34 \mathrm{Ca}$ & $0,34 \mathrm{Ca}$ & 11,4 & 11,3 \\
80 & 37,57 & 33,79 & $0,86 \mathrm{BCa}$ & $1,17 \mathrm{BCa}$ & 28,7 & 39,0 \\
106 & 49,67 & 31,05 & $3,58 \mathrm{ABa}$ & $2,46 \mathrm{BCa}$ & 119,3 & 89,0 \\
134 & 19,69 & 29,95 & $1,48 \mathrm{ABCa}$ & $3,05 \mathrm{ABa}$ & 49,3 & 101,7 \\
168 & 50,56 & 55,62 & $3,68 \mathrm{Ab}$ & $5,76 \mathrm{Aa}$ & 122,7 & 192,0 \\
\hline
\end{tabular}

$\mathrm{dms}$ (Tukey) $5 \%=2,74$

C.V. $=60,63 \%$ 
ta, sendo a concentração depois desse período maior, aumentando lentamente até aos 134 dias, nas duas 1 inhagens. 0 valor da concentração encontrado na ültima amostragem, aos 168 dias é menor que o valor da concentração presente até aos 50 dias.

GLINSKI et alii (1973) encontraram uma concentração média de ferro na época da colheita de 256,5 ppm, quando analisaram as partes da planta. A concentração de ferro na colza, considerando todas as partes da planta, na última amostragem é maior nas duas linhagens.

\subsubsection{A cúmu 1o}

o acúmulo das duas linhagens é crescente até o fim do ciclo, não havendo época preferencial de absor ção, como se observa na Tabela 23 e Grä́ico 10.

As duas linhagens têm quantidades baixas de ferro até aos 80 dias, no inicio do florescimento aumentando a partir desse período gradativamente até a colheita.

Na ūitima amostragem, a linhagem 1530 revelou um teor de ferro acumulado bastante alto, diferindo da 1 inhagem 1504 . 
o ferro é o micronutriente encontrado em maior quantidade na colza, atingindo valores acumulados mui to maiores que a couve-flor cv. Piracicaba Precoce e o repôlho, cv. Shikidore, que chegam a extrair 130,0 e $157,1 \mathrm{~g} / \mathrm{ha}$, respectivamente de ferro em todo o seu desenvolvimento, segundo HAAG etalii (1982), que estudaram a nutrição mineral dessas duas hortaliças.

A quantidade total de ferro encontrada na colza é vista na Tabela 27 , para as duas 1 inhagens.

\subsubsection{Manganês}

\subsubsection{Concentração}

A 1 inhagem 1504 sofre mudanças nas concentrações do manganês na planta toda, de acordo com as épocas de amostragem, podendo ser maior ou menor com esses períodos. A Tabela 24 aponta o fato. A 1 inhagem 1530 apresenta uma diminuição gradativa na concentração até aos 134 dias.

MIKos (1976) na Polônia, encontrou uma concentração média final de manganês, analisando folhas, caule, raíz, flor, vagem e semente, de 66,0 ppm, maior que a con centração encontrada na mesma época, para a colza.

4.3.4.2. Acūmulo

Assim como o ferro, o acūmulo de manganês na 
planta è crescente com o seu crescimento. A Tabela 24 expõe os resultados encontrados em mg/planta e g/ha, sendo tais re sultados referentes a dados estimados apenas.

As considerações sobre o acūmulo de manganês pela colza sãofeitas a partir de dados observados, pelo fato de haver grande variação em relação aos dados estimados. A componente de primeiro grau foi significativa ao nível de $5 \%$ com um coeficiente de determinação $\left(R^{2}\right)$ muito baixo, correspondente a $58,67 \%$.

o desvio foi significativo para a componente de quarto grau, porém, optou-se para: interpretação dos dados relativos a significância de primeiro grau.

As duas 1 inhagens extraem baixa quantidade de manganês até aos 80 dias, no início do florescimento, aumentando gradativamente a partir desse período até a colheita. O Grä́fico 11 ilustra o fenômeno. Não há diferença entre o acūmulo de manganês nas duas linhagens, exceto na ūltima amostragem, onde há maior extração pela linhagem 1530.

0 manganês é o segundo micronutriente mais absorvido pela colza, vindo logo após oferro, como apresenta a Tabela 27 .

HAAG et alii (1982) encontraram o-manganês co- 

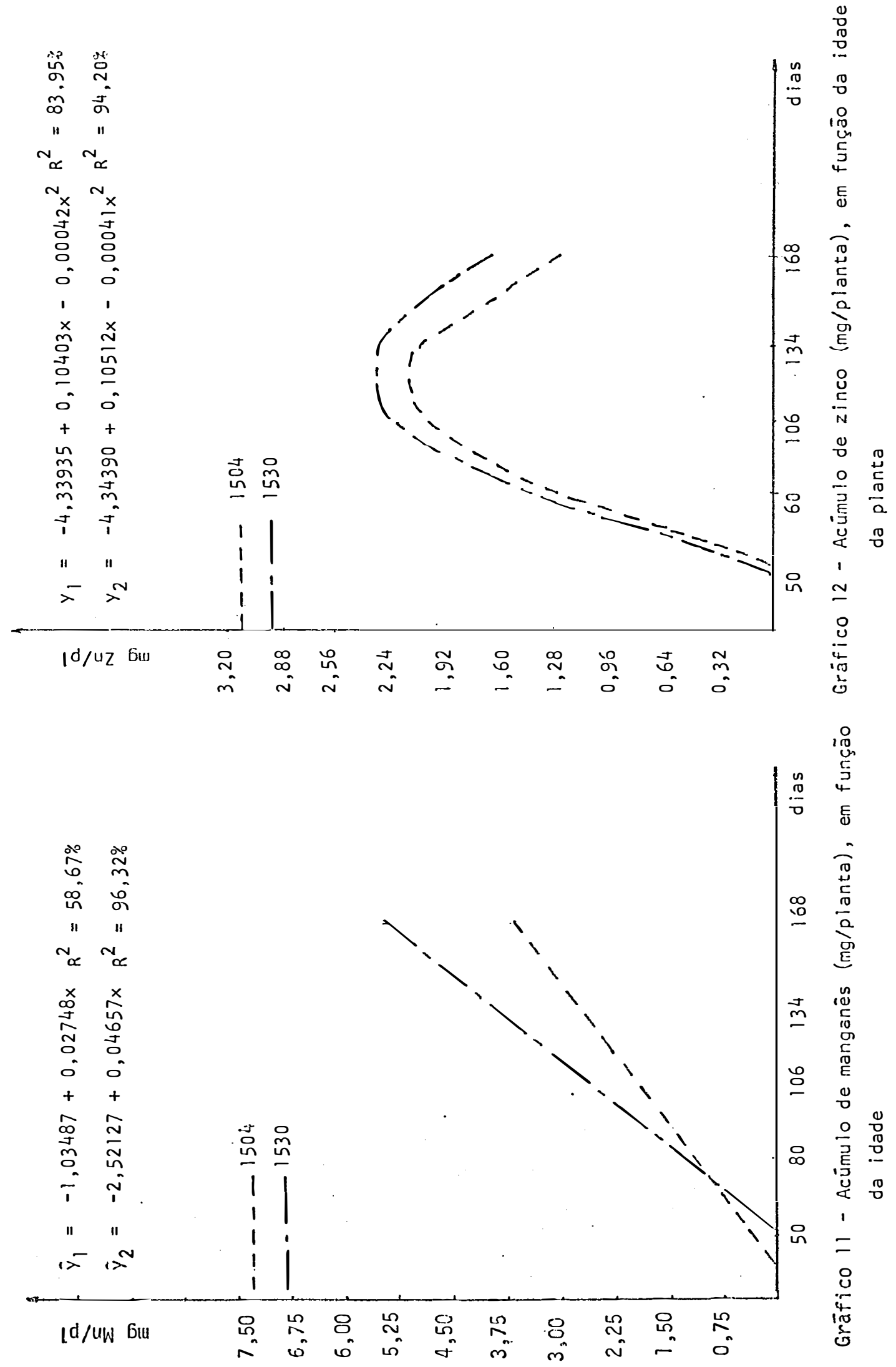
mo o quarto nutriente mais absorvido pela couve-flor cv. Pira cicaba Precoce e repôlho cv. Shikidore, havendo na planta 84,0 e 40,2 g/ha, considerando planta inteira e cabeça, sendo menos exigentes no elemento em relação a colza.

\subsubsection{Zinco}

\subsubsection{Concentração}

A diminuição da concentração do zinco na planta é gradativa com o aumento da matéria seca, como se pode notar na Tabela 25 .

MIKOS (1976) e GLINSKI et a $i$ i (1973) encontra ram quantidades médias no final do desenvolvimento da cultura de 102,0 e 106,9 ppm do elemento. Esses dados são maiores que os encontrados no presente trabalho.

\subsubsection{Acūmulo}

As Tabelas 25 e 26 expõem as quantidades acumuladas de zinco na planta e o Gráfico 12 ilustra o fato.

As duas linhagens têm baixa exigência nes-
se elemento até 80 dias, no início do florescimento,


Tabela 25 - Concentração e acúmulo totais de Zinco na planta, em ppm, mg/planta e g/ha, para os linhagens 1504 e 1530 (Mẻdia de 4 repetições).

\begin{tabular}{ccccccc}
\hline $\begin{array}{c}\text { Dias apös } \\
\text { emergencia }\end{array}$ & \multicolumn{2}{c}{$\mathrm{p} \mathrm{pm}$} & \multicolumn{2}{c}{$\mathrm{mg} / \mathrm{p} 1$} & \multicolumn{2}{c}{$\mathrm{g} / \mathrm{ha}$} \\
\hline & 1504 & 1530 & 1504 & 1530 & 1504 & 1530 \\
50 & 57,50 & 56,50 & $0,35 \mathrm{Da}$ & $0,38 \mathrm{Ca}$ & 11,7 & 12,6 \\
80 & 30,53 & 30,33 & $0,70 \mathrm{CDa}$ & $1,05 \mathrm{BCa}$ & 23,3 & 35,0 \\
106 & 33,65 & 25,70 & $2,43 \mathrm{Aa}$ & $2,42 \mathrm{Aa}$ & 81,0 & 80,7 \\
134 & 25,36 & 22,65 & $1,98 \mathrm{ABa}$ & $2,29 \mathrm{Aa}$ & 66,0 & 76,3 \\
168 & 17,75 & 14,72 & $1,18 \mathrm{BCDa}$ & $1,57 \mathrm{ABa}$ & 39,3 & 52,3 \\
\hline
\end{tabular}

dms (Tukey) $5 \%=1,08$

C.V. $=38,87 \%$

Tabela 26 - Resultados referentes à época de maior absorção e a quantidade máxima acumulada de Zinco, pelas 1 inhagens 1504 e 1530 。

\begin{tabular}{cccc}
\hline Tinhagem & (dias) & $\begin{array}{c}\text { Ponto de Maxima } \\
(\mathrm{mg} / \mathrm{p} 1)\end{array}$ & $(\mathrm{g} / \mathrm{ha})$ \\
\hline 1504 & 123 & 2,07 & 69,0 \\
1530 & 127 & 2,32 & 77,3 \\
\hline
\end{tabular}


aumentando até aos 106 dias em pleno florescimento, com um máximo atingido aos 123 e 127 dias para as 1 inhagens 1504 e 1530, no fim do florescimento, de acordo com dados estimados. 0 máximo estimado, ilustrado na Tabela 26 é de 2,07 e $2,32 \mathrm{mg} / \mathrm{pl}, 69,0$ e $77,3 \mathrm{~g} / \mathrm{ha}$ para as duas 1 inhagens. Não há diferença na exigência do zinco, entre as duas linhagens em todo o desenvolvimento da planta.

o zinco é o quarto nutriente mais acumulado pela colza, depois do ferro, manganês e boro. o máximo acumulado em relação aos outros micronutrientes é apontado na Tá be 1 a 27 .

A necessidade em zinco da colza é maior em relação a couve-flor cv. Precoce Piracicaba e repôlho Shikidore. HAAG et alii (1992) encontraram 35,0 e 61,0 g/ha do ele mento acumulado no fim do crescimento, nas duas hortaliças.

\subsection{Exportação de nutrientes pela colza}

A Tabela 27 aponta a extração máxima, exportação e porcentagem exportada de macro e micronutrientes, em relação ao máximo acumulado pela planta.

A exportação pelas sementes em kg/ha é maiorna linhagem 1530; porém, em relação a mesma quantidade de semente produzida, por exemplo, para uma tonelada, essa di- 
ferença è muito pequena. Isso é explicado pelo mator crescimento da planta e maior quantidade de sementes produzidas pe 1a 1 inhagem 1530 .

A extração dos macronutrientes por tonelada de semente segue a seguinte ordem, para as duas linhagens: nitrogênio, fósforo, potāssio = cálcio, enxofre e magnésio. COURPRON et alii (1973), encontraram ordem diferente de extração onde os mais extraídos são nitrogênio e enxôfre e os menos extraídos são magnésio e fósforo. ANDERSON et alii (1958) concordam com os resultados do trabalho em questão, encontrando a mesma sequência na extração de nutrientes.

A extração dos micronutrientes por tonelada de semente segue a seguinte ordem para as duas linhagens: manganês, ferro, zinco, boro e cobre.

A porcentagem de extração pelas sementes, em relação ao acúmulo máximo de macronutrientes é maior para o fósforo, nitrogênio, magnésio, enxôfre, cālcio e potássio para as duas linhagens. Em relação aos micronutrientes é maior para o manganês e zinco, cobre, boro e ferro, para as duas linhagens.

Tendo em vista a maior exportação de nutrientes em relação ao máximo absorvido pela cultura, pode-se dizer que o nitrogênio, fósforo, magnésio e enxôfre, são os 
nutrientes que menos retornam ao solo, devendo ser mais adicionados a este para suprir a exigência da plenta, em relação ao potássio e cálcio que são pouco exportados com a colheita. 


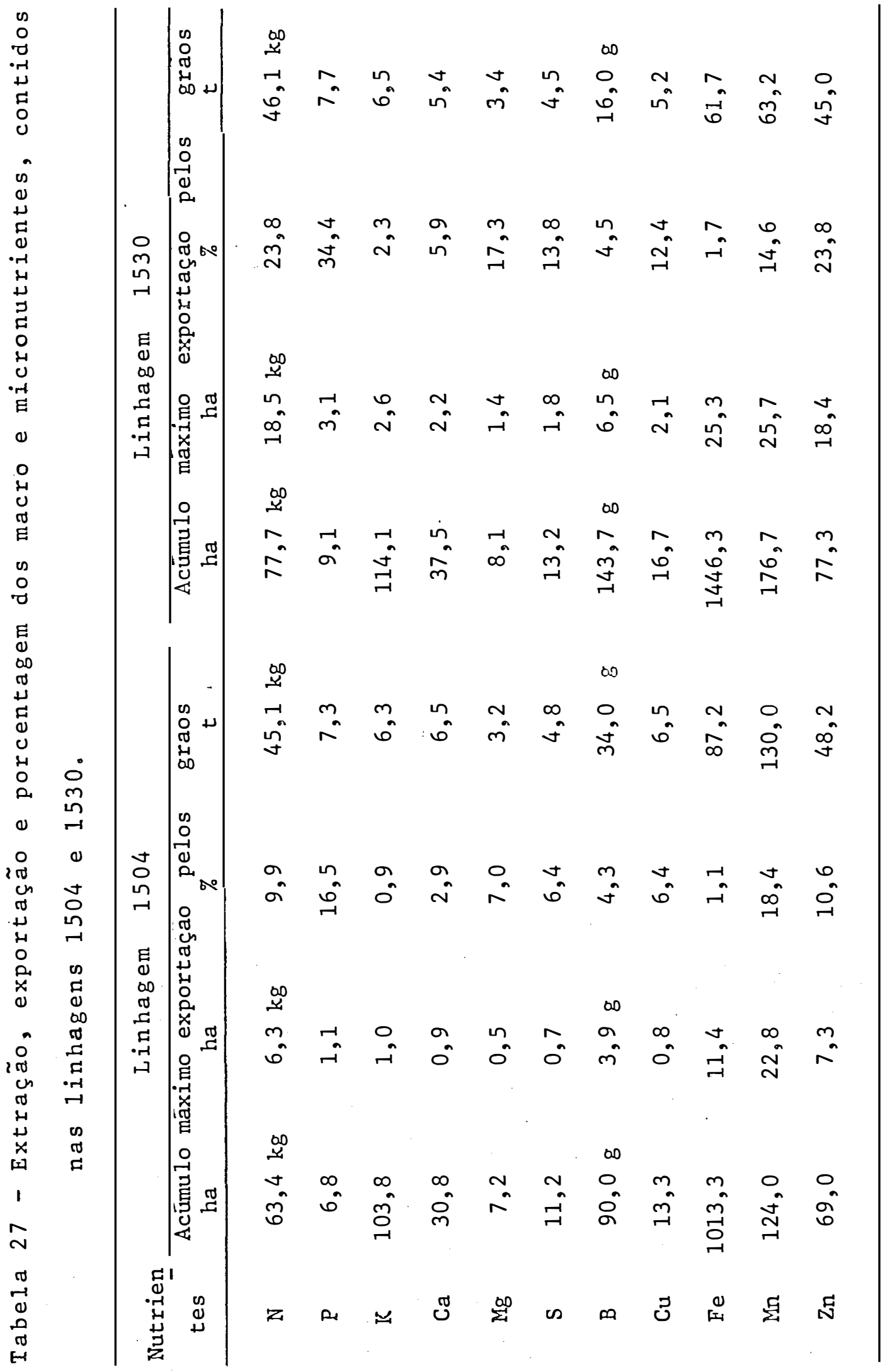




\section{CONCLUSOES}

\subsection{Crescimento}

o crescimento é continuo e crescente até atin gir um ponto de máximo acúmulo de matēria seca. E lento no início, sofrendo aceleração a partir dos 80 dias.

Na época de máximo crescimento da planta, encontrou-se $2.540,0$ e $3.700,0 \mathrm{~kg} / \mathrm{ha}$ de matéria seca para as Iinhagens 1504 e 1530 , tendo essa $\bar{u} 1$ tima linhagem atingido esse valor máximo, num tempo maior em relação à linhagem 1504, obtendo em todo o ciclo da cultura valores superiores de matēria seca.

\subsection{Concentração de nutrientes}

A concentração dos macronutrientes diminui 
com a idade da planta sem variação entre as linhagens.

Os macronutrientes encontrados em maior .concentração são em ordem decrescente: potássio, nitrogênio, cál cio, enxôfre, magnésio e fósforo.

A concentração dos micronutrientes também diminui com o aumento da matéria seca, exceto para ferro e man ganês, onde hà um ligeiro aumento depois dos 106 dias, em pleno florescimento, até o fim da maturação dos grãos.

Os micronutrientes encontrados em maior con centração em ordem dec்rescente são: ferro, manganês, boro, zinco e cobre.

\subsection{Acūmulo de nutrientes.}

o acúmulo de nutrientes acompanha a produção de matéria seca, lenta no início, com aceleração a partir do desenvolvimento e produção contínua de frutos.

A absorção do ferro e manganês é continua e gradativa, não se verificando ponto de máximo acúmulo na planta.

o período de máxima extração de nutrientes é de 120 a 139 dias, exceto para o cobre, que atingiu essa fase aos 164 dias na 1 inhagem 1530. Essa linhagem apresenta o período de máxima extraçao após o período atingido pela li- 
nhagem 1504 .

As quantidades máximas de macronutrientes acumuladas na planta toda, obedece à seguinte ordem, em kg/ $\mathrm{ha}: \mathrm{K}-103,8 ; \mathrm{N}-63,4 ; \mathrm{Ca}-30,8 ; \mathrm{S}-11,2 ; \mathrm{Mg}-7,2$; $\mathrm{P}-6,8$, para a linhagem $1504 \in \mathrm{K}-114,1 ; \mathrm{N}-77,7$; Ca 37,$5 ; \mathrm{S}-13,2 ; \mathrm{P}-9,1 ; \mathrm{Mg}-8,1$, para a 1inhagem 1530 .

As quantidades máximas de micronutrientes acumuladas na planta toda, obedece à seguinte ordem, em g/ha: Fe - $1.013,3 ; \mathrm{Mn}-124,0 ; \mathrm{B}-90,0 ; \mathrm{Zn}-69,0 ; \mathrm{Cu}-$ 13,3 para a linhagem 1504 e Fe - 1.446,3; Mn - 176,7; B 143,$7 ; \mathrm{Zn}_{\mathrm{n}}-77,3 ; \mathrm{Cu}-16,7$, para a linhagem 1530 .

\subsection{Exportação de nutrientes pelas sementes na colheita}

As quantidades de macronutrientes exportạ das através da colheita por tonelada de sementes, corres pondem em ordem decrescente a: N - 45,10 kg; $\mathrm{P}-7,30 \mathrm{~kg}$; $\mathrm{Ca}-6,50 \mathrm{~kg} ; \mathrm{K}-6,35 \mathrm{~kg} ; \mathrm{S}-4,78 \mathrm{~kg} ; \mathrm{Mg}-3,22 \mathrm{~kg}$ para a 1inhagem 1504 e $\mathrm{N}-46,12 \mathrm{~kg} ; \mathrm{P}-7,67 \mathrm{~kg} ; \mathrm{K}-6,52 \mathrm{Kg}$; $\mathrm{Ca}-5,45 \mathrm{~kg}$ e S $-4,50 \mathrm{~kg} ; \mathrm{Mg}-3,42 \mathrm{~kg}$ para a linhagem 1530 。

As quantidades de micronutrientes exportadas através da colheita por ton em ordem decrescente a: Mn - 130,00g; Fe - 37,25g; $\mathrm{Zn}_{-}$ 
$48,25 \mathrm{~g} ; \mathrm{B}-34,00 \mathrm{~g} ; \mathrm{Cu}-6,50 \mathrm{~g}$ para a linhagem 1504 e $\mathrm{Mn}-63,25 \mathrm{~g} ; \mathrm{Fe}-61,75 \mathrm{~g} ; \mathrm{Zn}-45,0 \mathrm{~g} ; \mathrm{B}-16,0 \mathrm{~g} ; \mathrm{Cu}-$ $5,25 \mathrm{~g}$, para a linhagem 1530 . 


\section{LITERATURA CITADA}

ANDERSON, G.; R. OLERED e G. OLSSON, 1958. The uptake of nutrients by wintèr rape. Zeitschrif fur Acker und Pflanzenbau, Sval8f, 107:171-9.

BRIOUX, C. 1923. Progression of the uptake of fertilizer nutrients in winter rape. Annales de la Science Agronomique Française Etrangére, 1-21.

COMITÊ DA COLZA. 1931. Sistema de produção para a colza oleaginosa. Trigo e Soja, Boletim Técnico, Porto Alegre, no $55,30 p$ 。

COURPRON, C.; M. MENET e E. PELABON. 1973. Fertilizing winter colza on sandy soils of the Landes de Gascogne. Comptes Rendus des Seances de l'Academie d'Agriculture de France, Gascogne, 59: 194-205. 
FILGUEIRA，F.A.R., 1981. MANUAL DE OLERICULTURA：CULTURA E COMERCIALIZAÇÃO DE HORTALIÇAS。2a。 ed ' São Paulo. Agronômica Ceres, V. 1, 338p.

GERATH, H。; W. BORCHMANN e I. ZAJONC, 1975. The effect of micronutrient boron on yield development in winter rape, Brassica napus. Archiv fur Acker und Pflanzenbau und Bodenkunde, Ber1im, 19:781-92.

GLINSKI, J.; M. MIKOS e Z. WARDA, 1973. Distribution of trace elements in winter rape organs. Roczniki Nauk Rolniczych, Lublin, Série A, 99:63-70.

HAAG, H.P. e K॰ MINAMI. 1982. Nutrição mineral em hortali ças. Campinas. Fundação Cargill. 631 p.

HAAG, H.P. e K. MINAMI 1982. Micronutrientes em hortaliças. Fundação Cargill. $26 \mathrm{p}$.

HEMERLY, F。X. 1979. Perspectivas da colza no Brasil. Publicação da Empresa Brasileira de Pesquisa Agropecuäria. EMBRAPA, DTC, Brasilia, 40p。

HERATH, H.M.W. e D.P.ORMROD。 1971. Temperature effects on the response to sulphur of barley peas and rape. Plant and Soil, Vancouver, 35:635-46. 
HOLMES, M.R.J. e A.M. AINSLEY. 1977. Fertilizer requirements of spring oilseed rape. Journal of the science of Food and Agriculture, 28:301-11.

HOLMES, M.R.J. e A.M.AINSLEY. 1978. Seedbed fertilizer requirements of winter oilseed rape. Journal of the Science of Food and Agriculture, Ipswich, 29:657-66.

HOLMES,; M.R.J. e A.M.AINSLEY. 1979. Nitrogen top-dressing requirements of winter oilseed rape. Journal of the Science of Food and Agriculture, 30:119-28.

HOLMES, M.R.J. 1930. Nutrition of the oilseed rape crop. London, Applied Science Publisher Ltd. $158 \mathrm{p}$.

LEFEVRE, G. e P. LEFEVRE。 1957. Observations on the uptake of nutrients by winter rape. Annales Agronomiques, Amiens, Série A, $\underline{8}: 125-44$.

LEON, M. de; R.R. GARCIA; P. GONZALEZ; F. INSUA e A. ALCÂNTARA. 1973. La colza oleaginosa. Madrid, I.N.I.A. Departamento Nacional de Plantas oleaginosas. 20p. Andalucia. (I.N.I.A. Hoyas Divulgadoras, 17).

LOUISE, M.E. e M.E. PICARD. 1891. The cultivation of rape. Annales Agronomiques, Caen, 210-23. 
MAJUNDAR, D.K. 1965. Uptake of nitrogen and phosphate, seed sizes and response curves in rape seed. Indian Oilseeds Journal, New Delhi, $\underline{9}: 266-73$.

MIKOS, M. 1976. The influence of soil conditions and level of mineral fertilizing on the content of trace elements in winter rape. Annales Universitatis Mariae CurieSklodowska, Lublin, 19:247-263.

PIERRE, I。 1860. Studies on winter rape in relation to different organs and stages of growth. Annales de Chimie et de Physique, Caen, 60:129-97.

RACZ, G.P.; M.D. WEBBER; R.J. SOPER e R.A. HEDLIN. 1965. Phosphorus and nitrogen utilization by rape, flax and wheat. Agronomy Journal, Manitoba, 5ㅍ: 335-7.

RADET, E。 1955. Fertilizing winter rape in Champagne. Annales Agronomiques, Champagne, Série A, $\underline{5}: 922-35$.

RADET, E. 1956. Fertilization of winter rape in the Marne in 1955. Annales Agronomiques, Marne, Série A, $\underline{6}$ : $1078-83$.

RANZANI, G.; O. FREIRE; T. KINJO. 1966. Carta de Solos do Mu nicío de Piracicaba. Centro de Estudos de Solos ESALQ/ USP. Piracicaba. 
ROLLIER, M. and FERRIF, J.P. 1969。 Rape and sulphur。 0leagineux, $24: 491-6$.

ROLLIER, M. 1970. Rapessed and nitrogen. oleagineux, Versailles, $\underline{2} \underline{5}: 91-6$ 。

RURZKOWSKA, M. e S. LYSZCZ, 1975. The influence of NPK and $\mathrm{Cu}$ doses on the yield and the copper and nitrogen uptake by plants under the conditions of pot experiments. Pamietnik Pulawski, no 62, 229-5 。

SARRUGE, J.R. e H.P. HAAG, 1974. Anālises quỉmicas em plantas. Piracicaba, ESALQ/USP, 56p.

SCHULTZ, J.E.R. 1972. Investigations on the seasonal changes in dry matter production and uptake of mineral elements in winter rape (Brassica napus). Tidsskrift for Planteaul, Aarslev, $\underline{76: 415-35 .}$

SETZER, J。 1946. Contribuição para o estudo do clima do Estado de São Paulo. São Paulos Escolas Profissionais Salesianas, $239 \mathrm{p}$.

STUDER, R. 1969. Note sur les besoins et les exportations en Azote, Acide phosphorique, Potasse et Soufre du Colza. D'Hiver en Champagne Berrichonne. Comptes Rendus des Seances de 1 'Academie d'Agriculture de France, Champagne, 55: 273-82. 